\title{
Nonisothermal Hydrologic Transport Experimental Plan
}

Manuscript Completed: August 1992

Date Published: September 1992

Prepared by

T. C. Rasmussen, D. D. Evans

T. J. Nicholson, NRC Project Manager

Department of Hydrology and Water Resources

University of Arizona

Tucson, AZ 85721

Prepared for

Division of Regulatory Applications

Office of Nuclear Regulatory Research

U.S. Nuclear Regulatory Commission

Washington, DC 20555

NRC FIN L1282 


\section{OTHER REPORTS IN THIS SERIES}

Evans, D.D., 1983, Unsaturated Flow and Transport Through Fractured Rock - Related to High-Level Waste Repositories, NUREG/CR-3206, 231 pp.

Schrauf, T.W. and D.D. Evans, 1984, Relationship Between the Gas Conductivity and Geometry of a Natural Fracture, NUREG/CR-3680, $131 \mathrm{pp}$.

Huang, C. and D.D. Evans, 1985, A 3-Dimensional Computer Model to Simulate Fluid Flow and Contaminant Transport Through a Rock Fracture System, NUREG/CR-4042, 109 pp.

Green, R.T. and D.D. Evans, 1987, Radionuclide Transport as Vapor Through Unsaturated Fractured Rock, NUREG-CR-4654, 163 pp.

Rasmussen, T.C. and D.D. Evans, 1987, Unsaturated Flow and Transport Through Fractured Rock - Related to High-Level Waste Repositories, NUREG/CR-4655, 474 pp.

Yeh, T.C.J., T.C. Rasmussen and D.D. Evans, 1988, Simulation of Liquid and Vapor Movement in Unsaturated Fractured Rock at the Apache Leap Tuff Site: Models and Strategies, NUREG/CR-5097, $73 \mathrm{pp}$.

Weber, D.S. and D.D. Evans, 1988, Stable Isotopes of Authigenic Minerals in Variably-Saturated Fractured Tuff, NUREG/CR-5255, 70 pp.

Rasmussen, T.C. and D.D. Evans, 1989, Fluid Flow and Solute Transport Modeling Through ThreeDimensional Networks of Variably Saturated Discrete Fractures, NUREG/CR-5239, 193 pp.

Chuang, Y., W.R. Haldeman, T.C. Rasmussen, and D.D. Evans, 1990, Laboratory Analysis of Fluid Flow and Solute Transport Through a Variably Saturated Fracture Embedded in Porous Tuff, NUREG/CR$5482,328 \mathrm{pp}$.

Rasmussen, T.C., D.D. Evans, P.J. Sheets and J.H. Blanford, 1990, Unsaturated Fractured Rock Characterization Methods and Data Sets at the Apache Leap Tuff Site, NUREG/CR-5596, 139 pp.

Evans, D.D. and T.C. Rasmussen, 1991, Unsaturated Flow and Transport Through Fractured Rock Related to High-Level Waste Repositories, Final Report - Phase III, NUREG/CR-5581, 75 pp. 


\section{DISCLAIMER}

This report was prepared as an account of work sponsored by an agency of the United States Government. Neither the United States Government nor any agency thereof, nor any of their employees, make any warranty, express or implied, or assumes any legal liability or responsibility for the accuracy, completeness, or usefulness of any information, apparatus, product, or process disclosed, or represents that its use would not infringe privately owned rights. Reference herein to any specific commercial product, process, or service by trade name, trademark, manufacturer, or otherwise does not necessarily constitute or imply its endorsement, recommendation, or favoring by the United States Government or any agency thereof. The views and opinions of authors expressed herein do not necessarily state or reflect those of the United States Government or any agency thereof. 


\section{DISCLAIMER}

Portions of this document may be illegible in electronic image products. Images are produced from the best available original document. 


\begin{abstract}
A field heater experimental plan is presented for investigating hydrologic transport processes in unsaturated fractured rock related to the disposal of high-level radioactive waste (HLW) in an underground repository. The experimental plan provides a methodology for obtaining data required for evaluating conceptual and computer models related to HLW isolation in an environment where significant heat energy is produced. Coupled-process models are currently limited by the lack of validation data appropriate for field scales that incorporate relevant transport processes. Presented in this document is a discussion of previous nonisothermal experiments. Processes expected to dominate heat-driven liquid, vapor, gas, and solute flow during the experiment are explained, and the conceptual model for nonisothermal flow and transport in unsaturated, fractured rock is described. Of particular concern is the ability to confirm the hypothesized conceptual model, specifically, the establishment of higher water saturation zones within the host rock around the heat source, and the establishment of countercurrent flow conditions within the host rock near the heat source. Field experimental plans are presented using the Apache Leap Tuff Site to illustrate the implementation of the proposed methodology. Both small-scale preliminary experiments and a long-term experiment are described.
\end{abstract}



1. INTRODUCTION

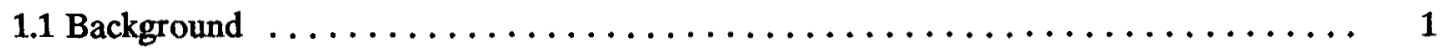

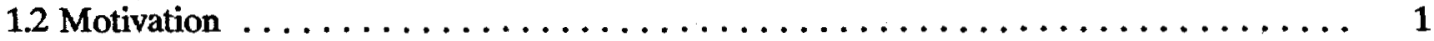

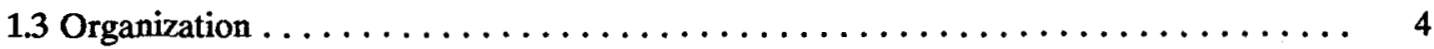

2. PREVIOUS STUDIES

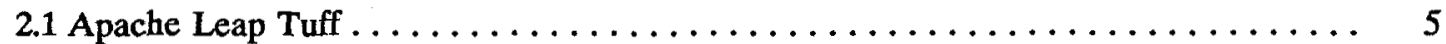

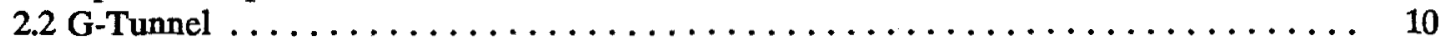

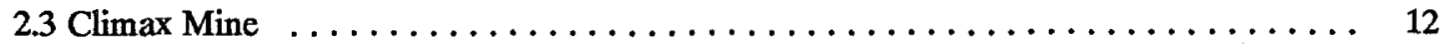

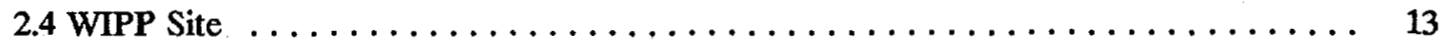

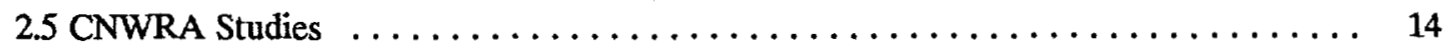

3. OVERVIEW

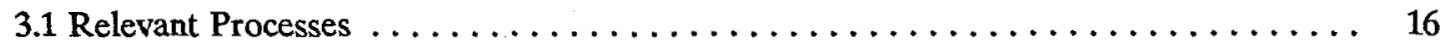

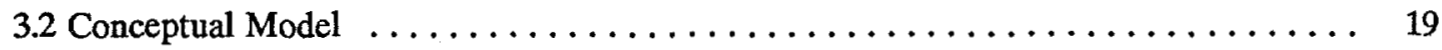

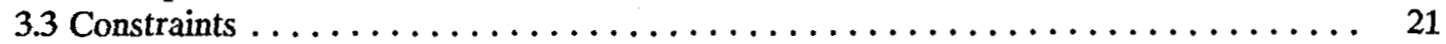

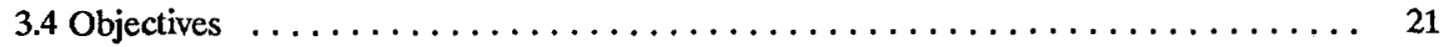

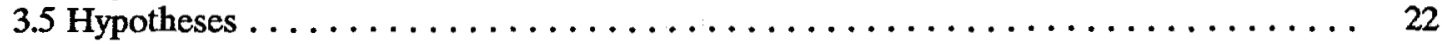

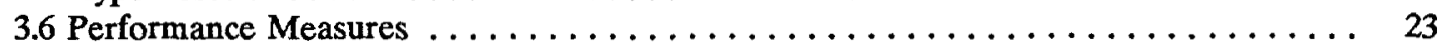

4. EXPERIMENTAL APPROACH

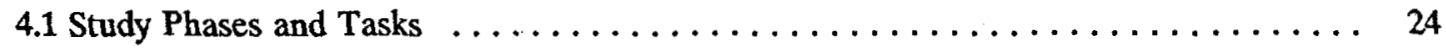

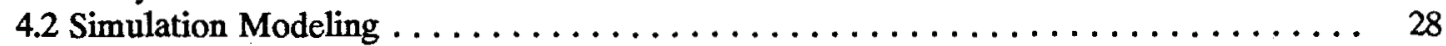

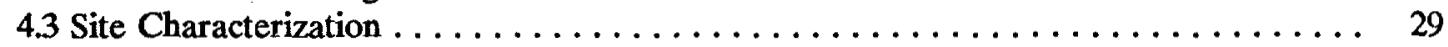

5. PRELIMINARY EXPERIMENTS

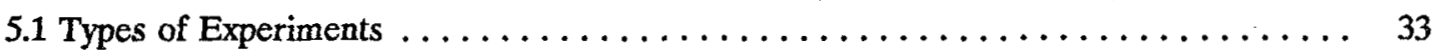

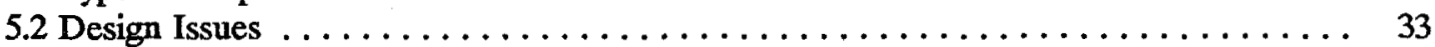

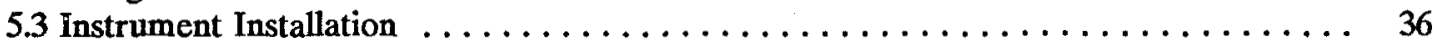

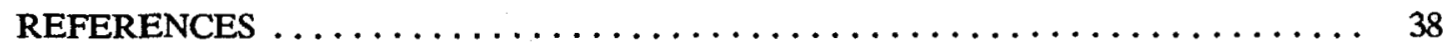




\section{LIST OF TABLES}

Table

1 Proposed U.S. DOE Site Characterization Studies $\ldots \ldots \ldots \ldots \ldots \ldots \ldots \ldots \ldots$

2 Processes, State Variables, and Selective Parameters $\ldots \ldots \ldots \ldots \ldots \ldots \ldots \ldots \ldots$

3 Knowledge of Flow and Transport Processes $\ldots \ldots \ldots \ldots \ldots \ldots \ldots \ldots \ldots \ldots$

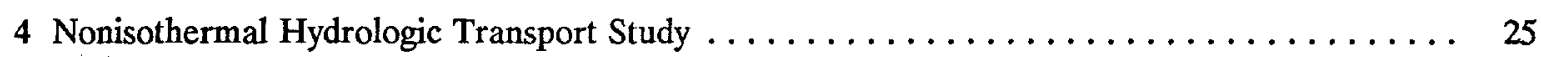

5 Experimental Tasks for Nonisothermal Experiment $\ldots \ldots \ldots \ldots \ldots \ldots \ldots \ldots \ldots \ldots$

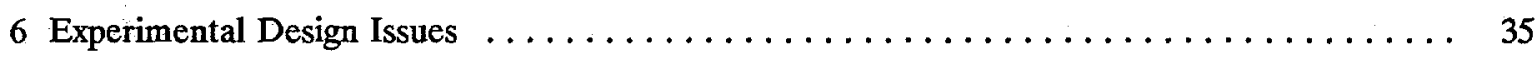

\section{LIST OF FIGURES}

Figure

1 Processes and interactions relevant to $\mathrm{HLW}$ migration $\ldots \ldots \ldots \ldots \ldots \ldots \ldots \ldots \ldots \ldots$

2 Solute concentration in partially saturated tuff core following

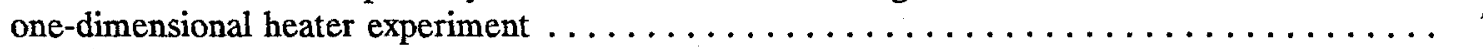

3 Water content distribution surrounding a heater source at the Apache Leap Tuff Site $\ldots \ldots \ldots \ldots \ldots \ldots \ldots \ldots \ldots \ldots \ldots \ldots \ldots \ldots \ldots$

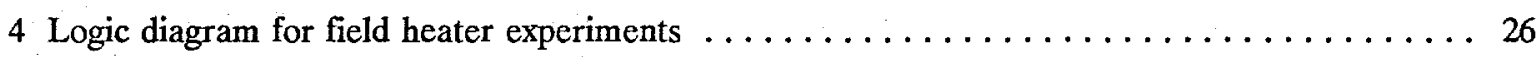

5 Schematic illustration of preliminary field heater experiments $\ldots \ldots \ldots \ldots \ldots \ldots \ldots$ 


\section{EXECUTIVE SUMMARY}

A field heater experimental plan is presented for investigating hydrologic transport processes in unsaturated fractured rock related to the disposal of high-level radioactive waste (HLW) in an underground repository. Analyses and predictions of fluid flow and transport in nonisothermal, unsaturated, fractured rock in the field are constrained by a lack of experimental experience in such media. The experimental plan provides methodologies for obtaining data required for evaluating conceptual and computer models related to HLW isolation in an environment where significant heat energy is produced by HLW. The experimental plan is intended to serve as a guide for planning and conducting a long-term, field-scale nonisothermal experiments at a specific site.

Also presented in this document is a summary of related nonisothermal experiments by U.S. NRC contractors at the University of Arizona and at the Center for Nuclear Waste Regulatory Analyses, and by U.S. DOE contractors at G-Tunnel and Climax Mine at the Nevada Test Site and at the Waste Isolation Pilot Plant in New Mexico. The previous experimental findings are summarized for the purpose of defining the state-of-knowledge at the time of this report. Processes expected to dominate heat-driven liquid, vapor, gas, and solute flow under anticipated experimental conditions are explained, and a conceptual model for nonisothermal flow and transport in unsaturated, fractured rock is described.

Of particular concern is the ability to confirm the establishment and significance of zones of lower and higher than ambient water content within the host rock around the heat source, and the establishment of countercurrent flow conditions (i.e., the heat pipe phenomenon) within the host rock near the heat source. Specific phases and tasks are recommended to implement the experiment, along with concerns regarding technological constraints and the ability to correctly identify whether models are performing adequately. A performance measure is presented which uses the mean and variance of the forecast error to evaluate the forecast model.

Plans for a series of field experiments at the Apache Leap Tuff Site (ALTS) in central Arizona are presented to illustrate the implementation of the nonisothermal experimental plan at a specific site. Three nonisothermal field experiments are considered, two of which are preliminary experiments leading to the execution of the final experiment. The preliminary experiments would be conducted to test equipment and procedures in unsaturated, unfractured rock as well as in rock incorporating a single discrete fracture. The final experiment would incorporate nonisothermal flow and transport processes over a larger domain with multiple fractures. In addition to evaluating data acquisition methods, the experiments are expected to provide data that can be compared with computer simulation projections of responses to the imposed thermal source.

Material properties at and near the ALTS heater sites are presented, and critical design and implementation considerations used to control expected outcomes of the experiment and to maximize the ability to evaluate conceptual and computer model performance are discussed. Computer simulation models should be employed to resolve design issues prior to conducting the experiments. Because of the reliance on computer simulation modeling studies, specific details of the experimental plan are not fully determined. Final design decisions should result from interaction between modelers and experimentalists during the planning phases. 


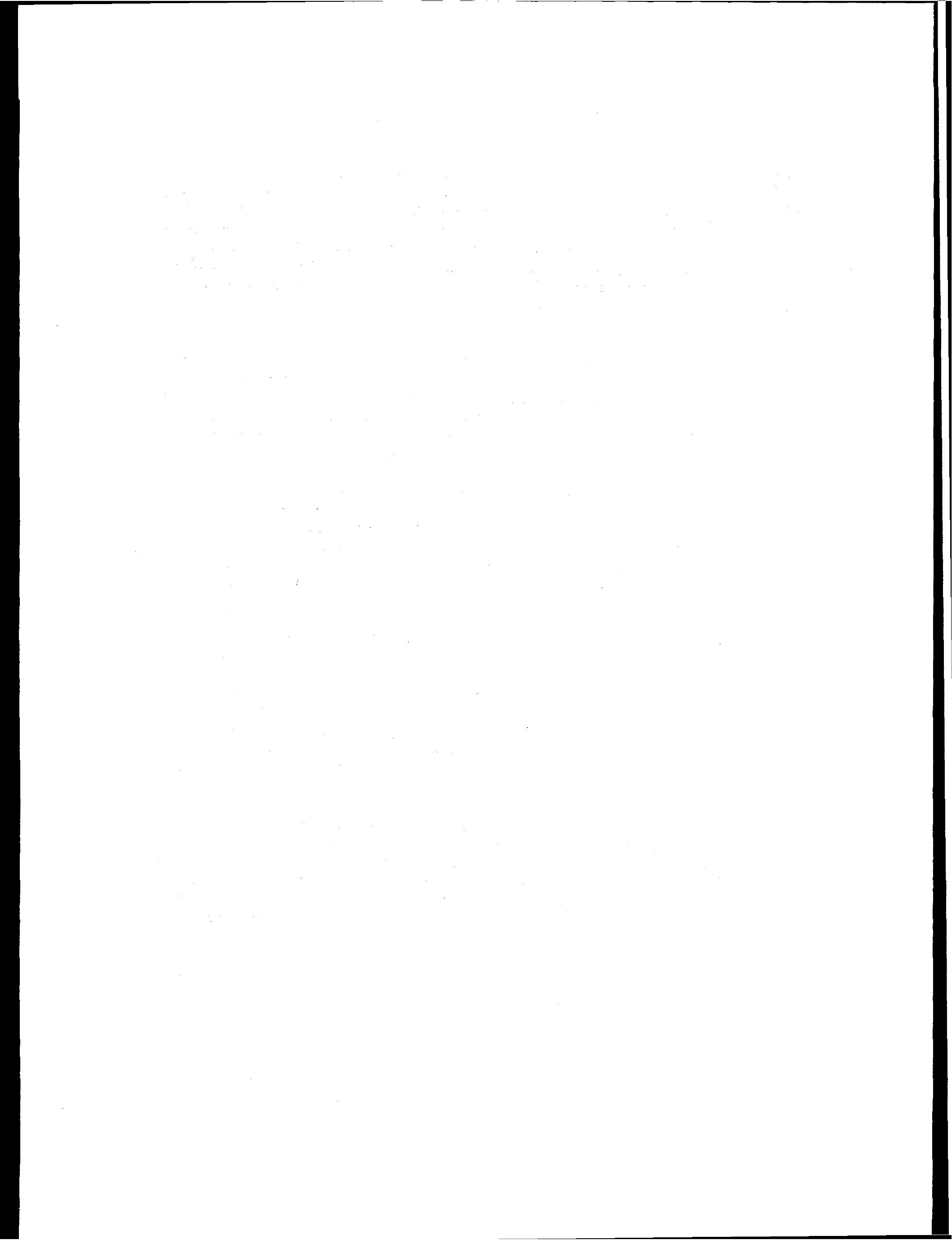




\section{ACKNOWLEDGEMENTS}

This document was prepared as part of a U.S. Nuclear Regulatory Contract to the University of Arizona (NRC-04-90-51, FIN L1282) entitled "Validation Studies for Assessing Unsaturated Flow and Transport Through Fractured Rock". The project monitor is Thomas J. Nicholson, who provided substantial input to the preparation of this document. Special acknowledgements should be made to INTRAVAL participants who provided review comments, including Shlomo Neuman, University of Arizona, Jaak Daemen, University of Nevada, Charlie Voss and Mark Cunnane, Golder Associates, and Wesley Patrick, Center for Nuclear Waste Regulatory Analyses. Also worth noting are the contributions of Abe Ramirez, Tom Buscheck, and John Nitao, Lawrence Livermore National Laboratories, and Joe Wang, Yvonne Tsang, and Karsten Pruess, Lawrence Berkeley Laboratory. 


\section{INTRODUCTION}

\subsection{Background}

High-level nuclear waste (HLW) confinement in underground, mined repositories depends upon the ability of the waste form and package to contain and isolate the waste under strongly nonisothermal conditions induced by radioactive decay of the HLW, and the ability of the geologic media to inhibit or retard the migration of the waste if the waste form or package should fail. The influence of large temperature gradients created by HLW decay should induce liquid and gas movement, as well as deformation of the geologic medium surrounding the waste package (Ramirez, 1990).

Transport of HLW may occur in a gaseous phase as vapors or aerosols, and in an aqueous phase as dissolved, complexed or colloidal constituents. Gravitational, pressure, density, osmotic, thermal and electrical gradients can induce gas and liquid flow in the geologic environment (deMarsily, 1981). Conditions which inhibit or retard gas and liquid flow through the geologic media include low absolute or relative permeabilities, large specific capacities, and long distances between the waste container and the accessible environment relative to HLW decay rates. Conditions which inhibit or retard HLW and daughter products relative to the fluid phase include molecular filtration, sorption, ion exclusion, radioactive decay, ion exchange, diffusion, volatilization and chemical precipitation (OECD, 1990). Characterization of HLW transport is complicated by coupling between processes, heterogeneities within geologic media, multiphase fluid flow, and thermal-mechanical induced deformation of the geologic media.

Important processes relevant to HLW transport are presented as Figure 1. The migration of HLW is the result of complex interactions between the physical setting (e.g., rock porosity and fracture density), as well as the hydraulic, pneumatic and thermal driving forces. It is the focus of this investigation to formulate an integrated experimental approach toward understanding coupled heat, water, air, and solute transport through mechanically deformable, fractured, variably saturated rock.

\subsection{Motivation}

As part of the U.S. Department of Energy (U.S. DOE) Site Characterization Plan (SCP) for the candidate HLW repository site at Yucca Mountain, Nevada, specific characterization experiments have been proposed by U.S. DOE (1988), summarized in Table 1. The table demonstrates that multiple processes are relevant, including geochemical, mineralogical, hydrologic, mechanical and thermal processes. Section 8.3.4.2 (a) relates the characterization program to a specific performance measure, specifically 10 CFR 60.135 , which states, in part:

"Packages for HLW shall be designed so that the in situ chemical, physical, and nuclear properties of the waste package and its interactions with the emplacement environment do not compromise the function of the waste packages or the performance of the underground facility or the geologic setting."

Of concern to thermohydrologic investigations is the inclusion of the key words: "and its interactions with the emplacement environment". Significant changes may be induced by the waste canister due to the thermal flux associated with HLW radioactive decay. Specific interactions such as those presented above must be evaluated in order to show compliance with this performance measure.

An assessment of the performance of a HLW repository and the geologic environment surrounding the repository requires that conceptual models be developed that incorporate the physical, hydraulic, pneumatic, chemical, mechanical, and thermal processes relevant to waste containment. Parameter specification and 


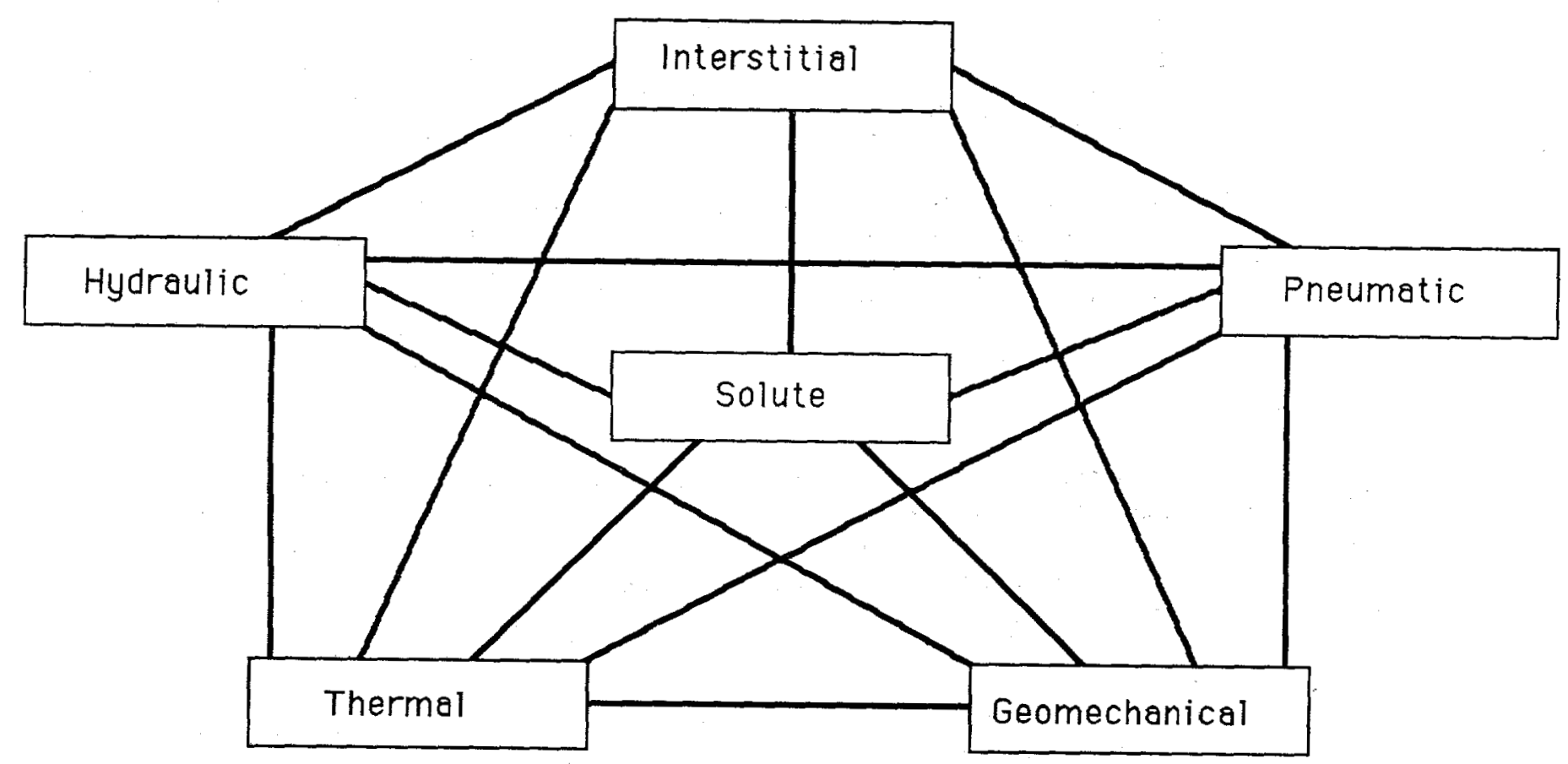

Figure 1: Processes and interactions relevant to HLW migration 
TABLE 1

Proposed U.S. DOE Site Characterization Studies (U.S. DOE, 1988)

SECTION

8.3.1.3.3

8.3.1.15.1.6

8.3.4.2.4.3

8.3.4.2.4.4

\section{PURPOSE}

Studies to provided information required on stability of minerals and glasses

- Natural analog of hydrothermal systems in tuff

- Kinetics and thermodynamics of mineral evolution

- Conceptual model of mineral evolution

In situ thermomechanical properties

o Heater experiment in unit TSw1

- Canister-scale heater experiment

o Yucca Mountain heated block

o Thermal stress measurements

o Heated room experiment

Issue 1.10: Have the characteristics and configurations of the waste packages been adequately established to:

(a) Show compliance with the postclosure design criteria of $10 \mathrm{CFR} 60.135$, and

(b) Provide information to support resolution of the performance issues?

Characterize chemical and mineralogical changes in the postemplacement environment.

o Rock-water interactions at elevated temperatures

- Dissolution of phases in the waste package environment

o Numerical analysis and modeling of rock-water interaction

Hydrologic properties of waste package environment

o Single-phase fluid system properties

o Two-phase fluid system properties

o Numerical analysis of flow and transport in laboratory systems

Mechanical attributes of the waste package environment

o Waste package environment stress field analysis

Engineered barrier system field tests

o Repository horizon near-field hydrologic properties

o Repository horizon rock-water interaction

o Numerical analyses of fluid flow and transport in the repository horizon near-field environment 
estimation can then proceed, and numerical or analytic models can be constructed to obtain forecasts of repository performance. Reliability of the conceptual and mathematical models must be estimated using experiments conducted at scales appropriate to the phenomena being evaluated. Alternate conceptual models should be compared in order to estimate forecast uncertainties.

The motivation for a field nonisothermal experiment is to provide data that can be used to evaluate mechanisms and processes. Computer models are an integral part of the evaluation, in that the effects of the mechanisms and processes may not be identifiable without simulation studies. Numerical modeling should be employed using identified processes and site-specific information for the purpose of predicting observed field behavior. The ability to successfully forecast the outcome of the experiment lends credibility not only to the conceptual understanding of the system, but also to the numerical procedures employed.

Simulation model predictions are uncertain due to the possible exclusion of relevant processes as well as the inability to correctly identify and estimate material properties which are highly variable. The significance of excluding various processes as opposed to the inability to estimate scale dependent material properties can be evaluated using laboratory tests conducted over short distance and time scales as well as field tests conducted over longer distance and time scales.

\subsection{Organization}

This chapter provides the background and motivation for performing field nonisothermal experiments. Chapter 2 summarizes previous experiments related to evaluating the environment surrounding the waste package. Field, laboratory and computer simulation experiments by University of Arizona researchers for conditions at the Apache Leap Tuff Site (ALTS) are presented. Other field experiments by U.S. DOE at G-Tunnel and the Climax Mine at the Nevada Test Site, at the WIPP site near Carlsbad, New Mexico, and laboratory and field experiments by the Center for Nuclear Waste Regulatory Analyses (CNWRA), a U.S. NRC contractor, are also summarized. Chapter 3 discusses how a nonisothermal field experiment should be conducted. The processes, conceptual model, objectives, hypotheses and performance measures are identified and described. Chapter 4 presents the proposed experimental methodology by detailing the phases and tasks to be performed. Chapter 5 describes preliminary nonisothermal tests to evaluate and test procedures and equipment, as well as to provide data for model performance evaluation. 


\section{PREVIOUS NONISOTHERMAL STUDIES}

In 1915, Bouyoucos experimentally observed the movement of soil water in response to an imposed temperature gradient. Gurr et al. (1952) experimentally demonstrated that liquid water moves towards the heated end of a partially saturated soil column, and that water vapor moves toward the cooler end where it condenses. This experimental work demonstrated the countercurrent, or heat pipe, phenomenon by showing that a steady thermal gradient can give rise to a liquid-vapor countercurrent in closed systems of unsaturated soil materials. The observed vapor flux was far greater at intermediate water contents than that predicted by a Fickian diffusion model modified for porous media.

Additional experimental work by Taylor and Cavazza (1954) found that the movement of water from warm to cool regions occurred mainly in the vapor phase and was accompanied by a liquid water return flow in response to the induced matric potential gradient. Taylor and Cavazza (as well as Cassel et al., 1969) report transfer coefficients for water vapor movement resulting from thermal gradients in various soil types. Philip and deVries (1957) tried to reconcile the observed vapor flux with the theory of diffusion in unsaturated porous media. Taylor and Cary (1960) developed an equation for heat and moisture transfer in unsaturated soil subjected to temperature gradients using the theory of thermodynamics of irreversible processes.

Cassel et al. (1969) measured moisture movement in response to steady temperature gradients in sealed cylinders of uniformly-packed, fine sandy loam at several different initial water contents. They also observed countercurrent flow with maximum moisture transfer at intermediate initial water contents. Their observed vapor fluxes agreed closely with that predicted by the theory of Philip and deVries, while the Cary and Taylor expression underestimated the vapor flux in all cases. Another experimental study by Trombel (1973) concluded that neither the Cary and Taylor model nor the Philip and deVries model were entirely successful in predicting the observed vapor flux in a closed, heated soil column.

\subsection{Apache Leap Tuff}

A number of laboratory, field and simulation experiments have been conducted at the University of Arizona as part of a U.S. Nuclear Regulatory Commission sponsored research program. The following sections describe nonisothermal experiments conducted in unsaturated, fractured rock at the Apache Leap Tuff Site or on cores obtained from the site.

\section{Laboratory Core Experiments}

Three laboratory countercurrent heating experiments were conducted by Davies (1987) using unsaturated, rock cores obtained from the Apache Leap Tuff. Slightly welded tuff cores approximately $6.4 \mathrm{~cm}$ in diameter and $13 \mathrm{~cm}$ in length were used in the first two experiments. A densely welded tuff core $9.5 \mathrm{~cm}$ in diameter and $12.2 \mathrm{~cm}$ in length was used in the third experiment. A vertical thermal gradient was established in the first heating experiment, while a horizontal gradient was used in the second and third experiments. The cores were subjected to a uniform thermal gradient of approximately $5 \mathrm{C} \mathrm{cm}^{-1}$ for 32 days, with maximum and minimum temperatures of approximately 70 and $10^{\circ} \mathrm{C}$, respectively.

The bulk density and initial, transient and final water content distributions within the cores were determined at one $\mathrm{cm}$ intervals along the cores using gamma attenuation methods. Temperatures within the cores were measured using thermocouples embedded $1.5 \mathrm{~cm}$ into the rock cores at regular intervals. Initial volumetric water contents within the densely welded tuff core were approximately 5.17 percent (a relative saturation of approximately 57 percent) and increased approximately 0.6 percent to a relative saturation of 64 percent near the cool face while decreasing approximately 1.2 percent to a relative saturation of 44 percent near the hot face. Temperature measurements indicated a near constant thermal gradient along the core. 
After heating, the cores were dissected into sections, crushed and analyzed for iodide (a soluble tracer which was initially added to the pore fluid) to detect ion movement caused by countercurrent flow and transport. Ion movement was assumed to occur in the liquid phase only. The results of the heating experiments clearly indicated the presence of countercurrent flow in the tuff cores (Figure 2). The iodide analysis indicated that more liquid return flow occurred in the nonwelded tuff core samples than in the densely welded samples. Gravitational forces did not appear to affect the experimental results.

The laboratory experiments conducted by Davies (1987) were modeled by McCartin et al. (1990) using TOUGH. Sensitivity analyses were used to evaluate the importance of characterization parameters on hydrologic and thermal responses by the simulated core. Because parameters for the core were not available, local sensitivity analyses were examined by varying a single parameter over its perceived range of uncertainty while holding other parameters at their initial base case values. Parameters examined in this way were permeability, binary diffusion coefficient, thermal conductivity, heat capacity and the characteristic curve shape. The findings by McCartin et al. indicated that:

- The water content distribution within the core was sensitive to the permeability, diffusion coefficient, and the shape of the characteristic curve;

- The water content distribution within the core was insensitive to the thermal properties, i.e., thermal conductivity and heat capacity;

- The temperature within the core was insensitive to all parametric variations attempted; and

- The simulated water content was generally characterized by a sharp spatial transition from dry (less than one percent) to wet (greater than sixty percent), while the observed data indicated a more gradual transition.

Results of the two-phase flow simulations were used to calculate the transport and redistribution of a dissolved tracer which was uniformly distributed throughout the core initially. A random walk particle tracking algorithm was developed to simulate the movement of solute based on the liquid flux calculated by TOUGH. Due to uncertainty in the parameters characterizing dispersion, three simulations were conducted which incorporated: advection, dispersion and molecular diffusion; advection and molecular diffusion; and advection alone. The three simulations resulted in almost identical results, with differences occurring only at the ends of the drillcore where the pure advection model predicts a higher solute concentration as compared to the other two models. Comparison of observed and simulated concentrations indicate good qualitative agreement, yet the experimental values of solute have more pronounced changes than were predicted by the model.

\section{Field Heater Experiment}

An exploratory field heater test was conducted by Davies (1987) in densely welded tuff in an abandoned road tunnel in Apache Leap Tuff. The experiment provided data and observations which can be used to help design the proposed field-scale experiment. Two nearly parallel, horizontal boreholes, $89 \mathrm{~cm}$ apart, $5 \mathrm{~cm}$ in diameter, and $15 \mathrm{~m}$ long were available for conducting the experiment. A heating element was placed six meters into one borehole, and a packer was installed next to the heater between the heater and the tunnel wall. Packers were also installed in the adjacent borehole at two locations to isolate an air space directly across from the heating element. The heater was positioned within an interval which included a fracture which appeared to intersect the packed off section of the observation borehole. Within the monitoring interval, three thermocouple psychrometers were installed for the purpose of monitoring rock water potential and temperature changes. A neutron probe was used to monitor water content changes in both boreholes prior to and following the heating phase. The initial water content distribution was determined using three neutron probe measurements at half-meter intervals in both boreholes. 


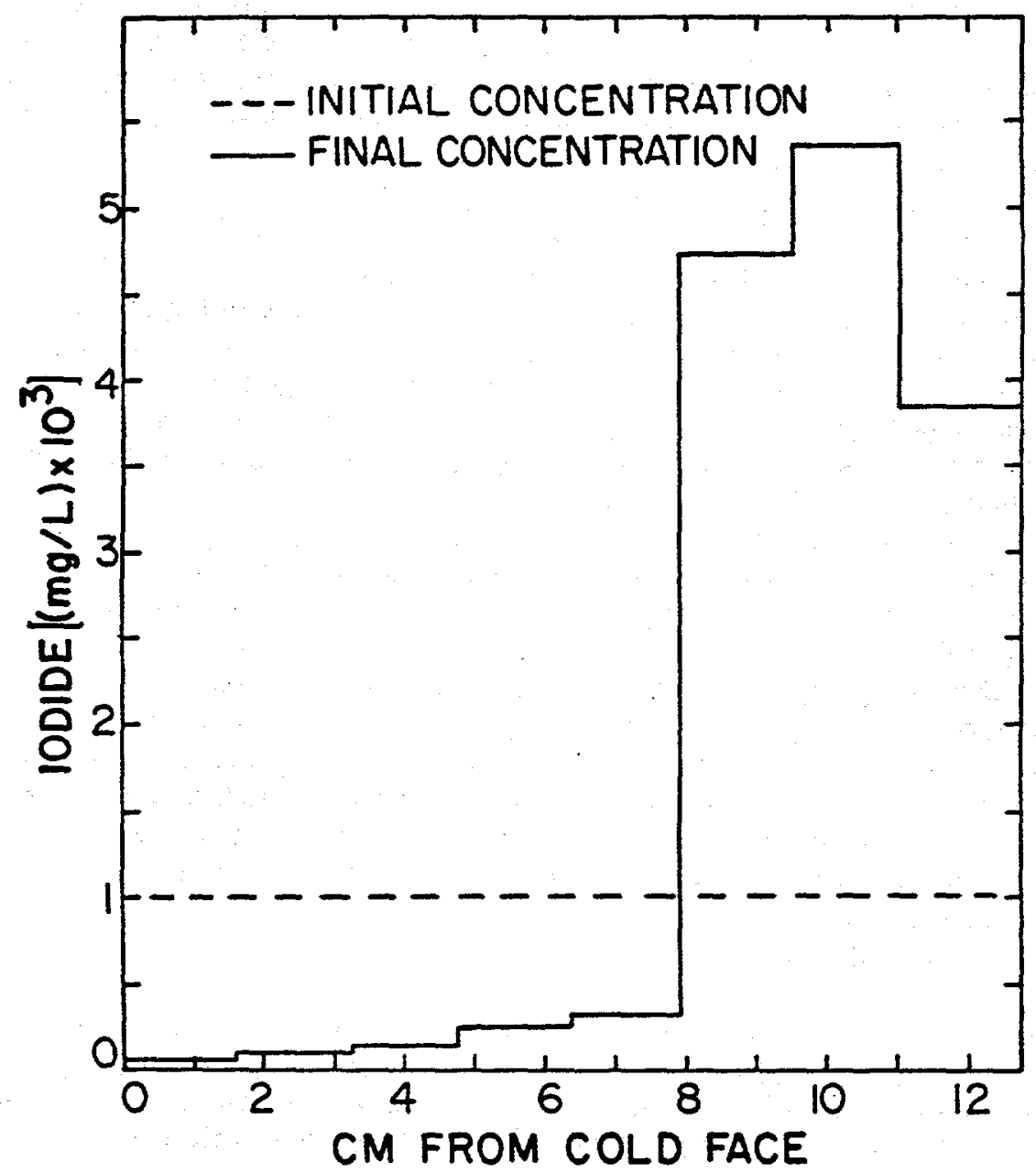

Figure 2: Solute concentration in partially saturated tuff core following one-dimensional heater experiment 
After an initial test using a $0.5 \mathrm{~kW}$ element heated for 65 hours, it was determined that no significant changes were observed, and a second experiment was conducted using a $1.5 \mathrm{~kW}$ element heated for 94 hours. During the second experiment the matric suction increased from $25 \mathrm{kPa}$ to approximately $900 \mathrm{kPa}$ in the observation borehole. The temperature in the observation borehole increased from an initial temperature of $20.0^{\circ} \mathrm{C}$ to $29.5^{\circ} \mathrm{C}$ at the time the heater was turned off, and then reached a maximum temperature of $31.1^{\circ} \mathrm{C}$ at 28 hours after the heater was turned off. Temperatures on the rock surface adjacent to the heater increased to $90^{\circ} \mathrm{C}$ at 48 hours after the heater was turned on, and continued to slowly rise to $91.5^{\circ} \mathrm{C}$ at 94 hours when the heater was turned off.

Liquid water was observed to discharge from the heater borehole during the heating phase. Free water also discharged from the observation borehole when the packers were deflated to allow water content measurements after the heater was turned off. The source of the water was most likely free water accumulation resulting from condensation behind the packers in the observation borehole, and along the borehole wall between the packer and the tunnel wall in the heater borehole.

Thirty minutes after the heater was turned off, the temperature sensor installed in the heated borehole noted a temperature of $81.6^{\circ} \mathrm{C}$. At this time the temperature sensor was moved so that it was situated at the center of where the heater had been installed. One hour after the heater was turned off the temperature of the rock adjacent to the former heating element was $132.3^{\circ} \mathrm{C}$, and at 2.75 hours it had fallen to $97.6^{\circ} \mathrm{C}$. In the observation borehole, the temperature had fallen to $27.0^{\circ} \mathrm{C}$ and the matric suction had returned to very near its initial value seven days after the heater was turned off. No water content changes were observed around the observation hole during the heating or cooling phases. Significant drying was observed in the heater borehole during the heating phase, and very slow wetting was observed following the heating phase. The water content surrounding the heater borehole had not returned to initial levels after 450 days (Figure 3 ).

Important lessons learned from this experiment can be used to guide subsequent experiments. In particular, it is recommended that multiple observation boreholes be installed at various distances from the heater source, and that multiple locations within the boreholes be instrumented for temperature and matric suction measurements. The locations should be isolated using inflatable packers with hydraulic and thermal properties similar to the surrounding geologic material. Redundant equipment should be installed at each location due to the long-term nature of the experiment, and also the difficulties associated with equipment maintenance and refurbishment.

\section{Simulation Experiments}

Cullinan (1983) investigated heat and fluid movement surrounding a heat source using a finite element model which incorporated coupled liquid and vapor flow in the rock matrix, a single, horizontal, discrete fracture intersecting the heat source, and vertical fractures intersecting the single horizontal fracture.

The assumptions were made that the bulk air phase was immobile, and that thermal rock and water expansion did not occur due to thermal changes. From the modeling investigation it can be hypothesized that rising temperature near the repository should induce vapor diffusion away from the repository and produce dry zones in and around the fracture near the heater, and wet zones in and around the fracture away from the heater. Variations in initial fracture water film thickness does not appear to have a significant effect on wet and dry zone configurations. Drainage fracture apertures and spacings, as well as host rock hydraulic properties should have much greater effects. The large volume of rock water appears to dominate the vapor diffusion process. Small vertical fractures should have the capacity to drain liquid water faster than it can diffuse away from the heat source. During both phases, moisture should move predominantly away from the heat source, as the temperature gradient should be directed away from the source. 


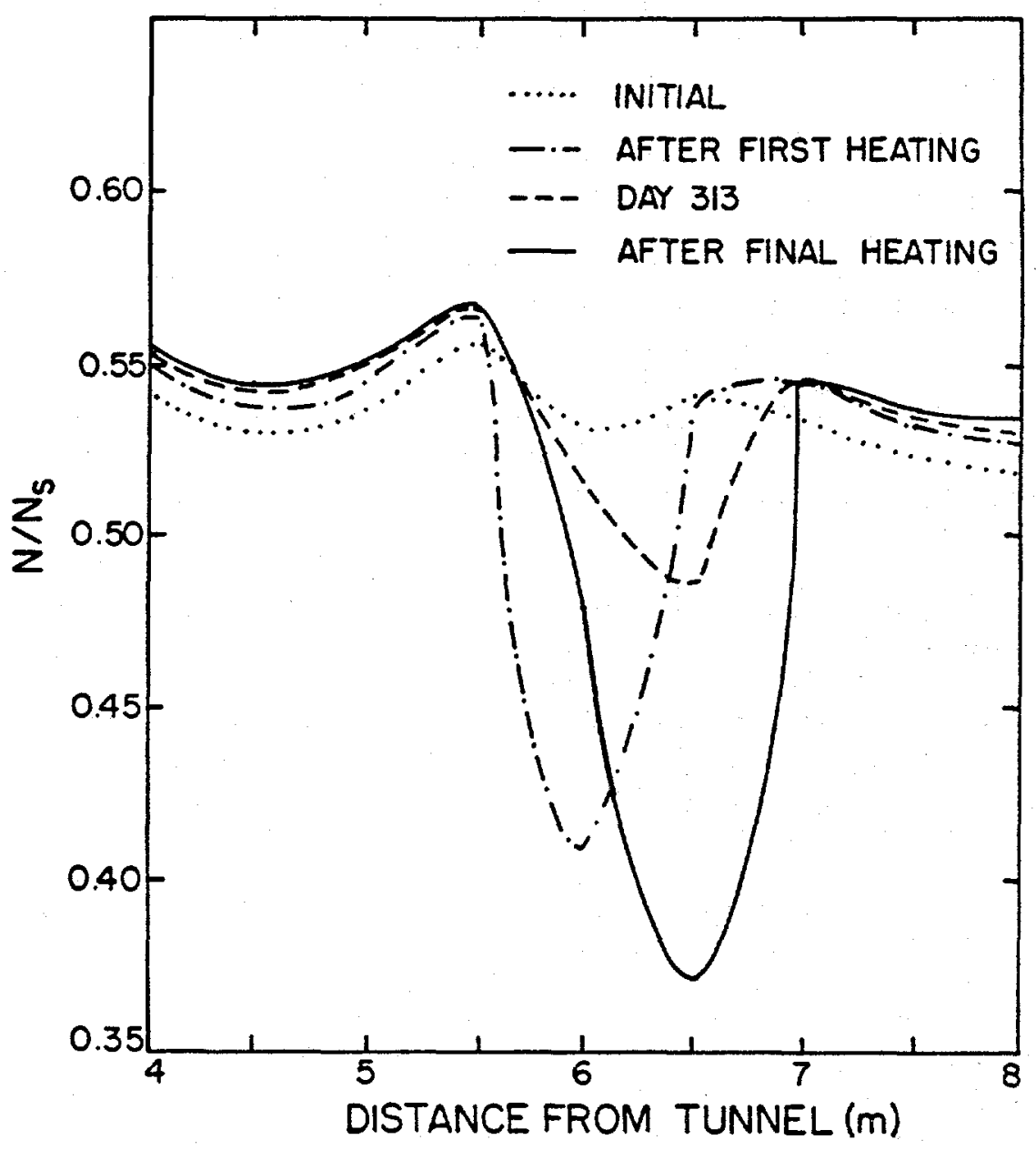

Figure 3: Water content distribution surrounding a heater source at the Apache Leap Tuff Site 


\subsection{G-Tunnel}

Heater experiments have been conducted in the G-Tunnel at the Nevada Test Site to evaluate the effect of a heat source on water movement in unsaturated fractured rock. The tunnel, which has since been closed, provided access to a welded ash flow tuff formation of the Grouse Canyon member of the Belted Range Tuff. This formation is of interest because it possesses similar thermal and hydraulic properties when compared with the Topopah Spring tuff at Yucca Mountain, which is the proposed HLW repository horizon. The Grouse Canyon Tuff exposed in G-tunnel is a moderately to densely welded tuff striking N55 W and dipping $9^{\circ} \mathrm{W}$. This formation is in the unsaturated zone but has a degree of saturation greater than sixty percent (and possibly greater than 85 percent) and a porosity ranging from ten to 25 percent.

A nonisothermal experiment (Ramirez and Daily, 1987; Daily and Ramirez, 1989; Ramirez et al., 1990) was used to obtain the hydraulic response of the fractured rock mass to a heat source. Electromagnetic (EM) tomography measurements were made between a series of horizontal boreholes drilled into the rib of a small diameter heater alcove. Both the heater and observation boreholes were horizontal with the observation boreholes being perpendicular to the heater hole. The boreholes defined two planes in the rock mass which used sampled for tomographic reconstruction. Each plane was two meters long by one meter wide. Both measurement planes were at least $3.4 \mathrm{~m}$ from a tunnel rib, with one plane lying parallel to heater borehole, and the other perpendicular. A fourth borehole was inclined a few degrees from the horizontal and was used to introduce distilled water into a fracture system which intersected the borehole. The borehole lay directly above the two tomographic planes, allowing the injected water to have a high likelihood of affecting the imaged rock mass.

The heating and cooling phases of the experiment lasted more than three months. A $1 \mathrm{~kW}$ electrical heater was operated for 34 days, during which time EM tomographic data and neutron logs were obtained. The boreholes were unsealed during the experiment to allow vapor transport and pressure equilibrium. During the last four days of the heating period, 473 liters of distilled water was introduced to the rock mass at a rate of four to eight liters per hour. The heater was then turned off and tomographic and neutron logs were taken as the rock cooled. Temperature logs in the immediate vicinity of the heater were not obtained due to bad thermocouple connections.

It can be concluded from this experiment that while the heater is operating, the rock water content decreases around the heater and the zone of desiccation increases over time. Water content anomalies coincided with fractures, indicating preferential drying along fractures. During the cooling phase, a large increase in water content was observed immediately around the heater, and water content anomalies again coincided with fractures, indicating preferential rewetting along the fracture planes. It was also observed that some thermocouple readings remained at the boiling point value for over a month during one experiment indicating that a countercurrent had developed (Zimmerman and Blanford, 1986).

\section{Characterization}

A series of characterization activities were performed in the field prior to the heater tests, but laboratory estimates of flow and transport properties were not obtained from cores. Fractures were observed every 30 to $50 \mathrm{~cm}$ using televideo logs. Single and cross-hole pneumatic tests were also performed. In one of the preliminary tests, a blue tracer was mixed with water, injected above the heater borehole, and tracked using inverse tomography. Subsequent corings of fractures demonstrated the presence of the tracer which matched the tomography results. Precise determination of borehole position was obtained using pretest borehole orientation surveys. For the tomography, borehole separation of approximately one meter was required, and maximum path lengths of one and a half meters were used. Scattering from boreholes and instrument packages was a significant problem associated with the EM tomography method. 
CONCLUSION: It is important to obtain as much characterization data as possible at field and laboratory scales prior to conducting the test, as well as following the test in order to evaluate the impacts of the experiment on rock properties. Characterization should focus on rock matrix and fracture parameters including physical, hydraulic, pneumatic, thermal, and mechanical properties.

\section{Construction}

The heater borehole was $30 \mathrm{~cm}$ in diameter, and the canister containing the heater was $20 \mathrm{~cm}$ in diameter. The heater borehole required seven weeks to drill the 10 meter length. The EM equipment was less than $2 \mathrm{~cm}$ in diameter. To fill the empty volumes in the observation boreholes, grout was used to prevent an airphase conduit. The grout was $30-40 \%$ sand in a lean cement ratio. A thick grout was used initially to prevent fracture penetration, allowed to set for 1 to 2 days, and then followed by the fluid grout. One problem was that the instrument tube tended to float in the grout to the top of the horizontal hole. A closed cell foam (FIRESTOP) was used as a seal in the vicinity of the heater to prevent vapor transport. It was observed that it would be best to grout around displacement instruments with sponge rubber. An inflatable rubber heat resistant packer was placed at the end of the heater. After removal of the packer following the completion of the heater experiment, the rubber surface showed a fracture impression and geochemical precipitates. A restraint was placed over each borehole to prevent ejection of packers in the event of a blowout.

CONCLUSION: It is important to minimize voids in the heater and observation boreholes. This can be accomplished by using grout, closed cell foam, or using heat resistant packers.

\section{Instrumentation}

No geomechanical data were collected due to time and cost constraints. This aspect was proposed for a followup experiment. K-type thermocouples obtained from the Climax experiment were used to measure temperatures. Some thermocouples were mounted in a rock placed between the heater and the rock wall. Three were placed below, and one above the heater. Other thermocouples were placed in nearby boreholes.

A combined neutron and gamma probe was used to measure porosity and water content. A CPN neutron probe was modified to include a gamma detector below the neutron probe, as opposed to the standard position around the probe. Also, to avoid failure in a high temperature environment, a thermistor was used to monitor probe temperature. When the probe temperature exceeded $70^{\circ} \mathrm{C}$, the probe was removed and allowed to cool.

A resonance cavity was used to measure the partial pressure of water vapor near the heater canister. There was a problem with condensation in the cavity leading to equipment failure. A nonlinear relationship between resonant frequency and water content was observed. The microwave resonator was placed on the end of the heater packer along with a capacitance sensor (humicap), which is also used for humidity measurements. The capacitance sensor worked reasonably well, but the microwave resonator failed due to condensation within the resonance chamber.

CONCLUSION: Instrumentation must be used which is compatible with the severe operating conditions expected around the heater borehole. Extreme care must be taken in positioning and selecting the monitoring equipment. Additional information on fracture water content must be obtained using technology which is currently unavailable.

\section{Observations}

During the heater tests, greater drying and heating was observed above the borehole than below. The observed temperature difference between the top and the bottom of the heater canister was approximately 
$40^{\circ} \mathrm{C}$, and may have been even greater. More temperature sensors should be required to examine canister temperature. The heat load also was observed to have an edge effect (the ends of the heater were cooler than the center), and the source appeared to go from a line source to a spherical source over time.

Matrix porosity was about thirteen percent, yet the change in water content was approximately 16 percent due to rock heating. The source of the extra three percent is still unknown. The effect of the drift boundary on water content, movement and temperatures may be important.

After the heater experiment, the pneumatic tests were repeated and showed higher permeabilities, presumably due to fracture enlargement: Small changes in fracture aperture can result in large changes in permeability, so thermomechanical properties may be required to evaluate the correlation between fracture displacement and permeabilities. Whether the fracture permeability increased due to fracture displacement, or to a reduction in water content, could not be determined.

The spatial coverage was determined to be inadequate because the observation boreholes were emplaced along essentially horizontal planes. Also, gravitational forces caused movement above and below the heater which could not be monitored. Water vapor was collected from the annulus between the heater canister and the heater borehole wall. Because the chemistry of collected water was not examined, no conclusions regarding geochemical processes can be made.

CONCLUSIONS: Inadequate monitoring of water contents, temperatures, water chemistry, matric potential, mechanical deformation, and the source term resulted in inconsistent and incomplete data. Emphasis should be placed on obtaining data which are as complete and reliable as possible. A major design issue is selecting the types and precision of data required and monitoring techniques to be employed.

\section{Modeling}

LLNL modeled the experimental results by assuming radial symmetry and ignoring gravity, but the failure to incorporate gravitational forces severely limited their analysis. To evaluate alternate conceptual models, they compared a matrix only model, with a single discrete fracture model, and with an equivalent continuum model. While estimated temperature profiles were similar for all three models, water content profiles were substantially different between models.

They noted that while rapidly heating the system yields immediate results, subboiling conditions requires an extremely long observation period. There was also a question regarding drying rate as a function of the fracture density, and whether a simplified analytic model developed by LLNL might accurately predict the drying rate.

CONCLUSION: Computer modeling activities must incorporate gravitational effects. A simplified analytic model which incorporates fracture density may be appropriate for predicting water drying rates.

\subsection{Climax Mine}

The Climax experiment did not investigate hydrologic processes, but focused instead on thermomechanical impacts of a subsurface heat source in the unsaturated zone (Wilder and Yow, 1984, 1987; Butkovich and Patrick, 1985; Montan and Patrick, 1986; Patrick, 1986). Three drifts were constructed, with a row of aged reactor fuel used as a heater source in the central drift, and two rows of electric heaters used as a heater source in the peripheral drifts aligned parallel to the central drift. Temperatures and mechanical displacements were monitored around the drifts. Initial temperatures of approximately $25^{\circ} \mathrm{C}$ rose to nearly $150^{\circ} \mathrm{C}$ during the course of the experiment. 
It was observed that shear displacement was important across fractures and shear zones, while normal displacements were generally recoverable and crushed rock zones displayed the greatest deviations from theory. A shortcoming of the Climax experiment was the failure to obtain motion measurements in all directions, as well as to record motion out to the undisturbed region. Also, it was observed that mechanical displacement had a significant impact on the hydrology in that free water was observed at a major fault and along associated fractures. Based on this observation it is recommended that mechanical and hydrologic measurements be obtained along fracture-borehole intersections.

To model geomechanical effects, the Adina-T code from MIT is the recommended structural code. Thermomechanical codes worked well at Climax for the rock matrix, but did not perform as well for fractures. It may be possible to attribute changes in bulk rock behavior entirely to fracture changes.

For nonisothermal conditions, thermocouples on displacement posts should be required to account for thermal expansion of reference rods. There could also be a difficulty with providing a perfect attachment of displacement instruments to rock. It would be best to use a J-Latch on a rod, but there is a question concerning creep. There should be mechanical backup in case of electrical failure. May want to investigate the use of a Goodman Jack.

CONCLUSION: It was concluded that hydrologic processes may be extremely sensitive to mechanical changes. Monitoring of thermomechanical responses is critical if a complete understanding of hydrologic transport is to be obtained. From knowledge gained during the Climax experiment, it is advised that only limited effort be placed on measuring fracture apertures, and that it would be better to measure changes in rock mass volume and relative fracture motion.

\subsection{WIPP Site}

A heater test was conducted at the Waste Isolation Pilot Plant (WIPP) facility near Carlsbad, New Mexico, in a bedded salt formation (Munson, 1983). The purpose of the experiment was to evaluate the waste package performance technology for simulated defense high-level waste. The large-scale, in situ tests were developed to overcome difficulties associated with small-scale experiments which ignored the field environment, including the effects of impurities, fractures, and naturally buffered $\mathrm{pH}$ and $\mathrm{Eh}$.

The heater source was a synthetic waste canister with a maximum thermal output of $1.5 \mathrm{~kW}$ with a jacket fabricated out of Inconel 600 pipe, $10.2 \mathrm{~cm}$ in diameter by $94 \mathrm{~cm}$ long. Various metal specimens were also clamped to the canister-heater for the purpose of conducting corrosion studies. Six backfills were placed in the annulus between the canister and the bedded salt:

- low-density ( $1.29 \mathrm{~g} \mathrm{~cm}^{-3}$, poured and manually tamped) powdered bentonite clay,

- low-density $\left(1.41 \mathrm{~g} \mathrm{~cm}^{-3}\right)$ bentonite-silica sand,

- low-density $\left(1.45 \mathrm{~g} \mathrm{~cm}^{-3}\right)$ bentonite-silica sand injected with 201 of brine into the heated backfill,

- annular compacts of high-density $\left(2.05 \mathrm{~g} \mathrm{~cm}^{-3}\right)$ bentonite-silica sand

- entrapped air, and

- finely crushed rock salt from WIPP $\left(1.3 \mathrm{~g} \mathrm{~cm}^{-3}\right)$.

The test emplacements were instrumented with multiple thermocouples, pressure gages for backfill swelling pressure measurements, electrical resistivity/moisture sensor devices, and vertical displacement gages to monitor canister movement. The instruments were connected to a data logger for frequent, automatic monitoring and recording. Most experiments were also equipped with gas sampling tubes, backfill coring tubes, and brine injection ports located at the salt-backfill interface. No instruments were placed in the bedded-salt formation. 
The tests lasted from between one to five months. Temperature measurements and profiles indicated that the effective thermal conductivities of the backfills at a maximum temperature of 150 to $250^{\circ} \mathrm{C}$ ranged from a low of 0.23 to $0.26 \mathrm{~W} \mathrm{~m}^{-1} \mathrm{~K}^{-1}$ for the low density bentonite, to a high of 1.05 to $1.30 \mathrm{~W} \mathrm{~m}^{-1} \mathrm{~K}^{-1}$ for the highdensity bentonite-silica sand. The effective thermal conductivity for air ranged from 0.7 to $1.3 \mathrm{~W} \mathrm{~m}^{-1} \mathrm{~K}^{-1}$.

No geochemical alterations were detected in any of the heated backfills. As part of waste package performance testing, it was observed that there was essentially negligible corrosion on all the nickel-based alloys, and the stainless steels, and the titanium alloys. Mild surface corrosion was observed on the lead, cast iron, and mild steel. There was, however, potentially serious corrosion due to pitting observed on the 2-1/4 Cr-1 Mo steel and, to a lesser extent, on the copper samples, both in the brine-injected backfill test.

\subsection{CNWRA Experiments}

Various laboratory and field experiments have been conducted by the Center for Nuclear Waste Regulatory Analyses (CNWRA, 1991). Laboratory experiments have focused on thermohydrologic interactions in synthetic materials with the purpose of providing data for model evaluation. In addition, a field program is underway to estimate the effects of seismic activity on the mechanical and geohydrologic response of underground structures in jointed rock.

\section{Laboratory Thermohydrologic Studies}

A laboratory experiment was conducted by Green et al. (1990) at CNWRA using a synthetic porous medium consisting of various mixes of silica glass beads packed and filled at a fixed water saturation. The test chamber dimensions are $14.6 \times 20.7 \times 1.9 \mathrm{~cm}$ thick. Endplates constructed of anodized aluminum were used on four sides, and the two larger surfaces were constructed of clear plastic. Two of the aluminum endplates were used as heat exchangers in order to maintain a one-dimensional horizontal temperature gradient across the test chamber. The side walls were insulated to minimize heat loss and fluctuations in temperature boundary conditions.

The porous medium consisted of equal volumes of 40 - and 80 -micrometer diameter glass beads. The beads were mechanically mixed and then saturated to 60 percent of saturation by volume. After the container was filled halfway with the bead mixture, an artificial fracture was emplaced by sprinkling 160 -micrometer diameter glass beads at an average thickness of $0.5 \mathrm{~mm}$ across the surface of the bead mixture. A uniformly thick fracture was not possible, however, by the nature in which the larger beads were emplaced. The remaining half of the container was then filled with the premixed, partially saturated glass beads. The porosity of the bead mixture was estimated to be approximately 34.5 percent. The characteristic curve and unsaturated hydraulic conductivity of the bead mixture were determined.

Once filled, the container was sealed except for two ports located in the side walls. The ports were used for injecting colored dyes into the medium, but were sealed when not in use. After sealing, the chamber was rotated until the endplates containing the heat exchangers were in a vertical position. The temperature of the endplates were then adjusted to impose a horizontal temperature gradient of $2.7 \mathrm{C} \mathrm{cm}^{-1}$. Initially, the left endplate was held at $60^{\circ} \mathrm{C}$ and the right endplate was held at $20^{\circ} \mathrm{C}$, but the gradient was later reversed. This second imposed temperature gradient was then maintained for the remainder of the experiment.

The movement of water was monitored visually and photographically, and by using gamma attenuation methods. Although the gamma ray measurements correlated positively with the observed moisture movement, insufficient resolution was provided by the device for any quantitative analysis. Visual data gathered during the experiment provided the only useful information. From the visual data, the initial direction of dye flow next to the heated end plate was downward to the bottom of the container, and then toward the interior of the chamber until the simulated fracture was encountered. As evidenced by the dye, water 
did not cross the fracture, but rather, it moved upward forming what appeared to be a convection cell. The dye became too dilute beyond this point to be used as an indicator of water flow direction or of the existence of the upper portion of the suspected convection cell.

A second observation of interest was the effect that the simulated fracture had on flow within the test container. Water appeared to flow up to, but not across, the fracture during the early stages of the experiment. Later in the experiment, after sufficient water had migrated to the cool side of the test container, and the moisture content of the bead mixture next to the fracture became sufficiently high so that the relatively large sized pores of the simulated fracture became saturated, water appeared to traverse the fracture to the other side of the container.

CONCLUSIONS: Discrete fractures oriented parallel to a heat source appear to interrupt the normal fluid movement associated with a heat pipe. Countercurrent conditions may exist on either or both sides of the heat pipe. Gravity-dominated convection cells appeared on both sides of the vertical fracture.

\section{Field Seismic Effects Study}

A study to evaluate the repository response to repetitive dynamic loadings is currently underway at the Lucky Friday Mine in Idaho (Hsiung et al., 1991). The coupling of mechanical and geohydrologic responses to seismic activity is the focus of this research effort by CNWRA (Brady et al., 1990). While not directly related to thermohydrologic processes, the research is related to coupled hydro-mechanical effects. Shortand long-term rock mass hydraulic and mechanical responses are related to mine excavation and associated seismic activities. Extensometers and piezometers have been installed in boreholes to monitor changes in position and fluid pressure at distances of $8 \mathrm{~m}$ and $365 \mathrm{~m}$, respectively, away from the mine excavation.

The ultimate objective of this study is to provide a complete data set to evaluate the performance of computer codes. Required information includes the geologic structure near the mine, rock mass and joint mechanical properties, mining history, location of source and associated velocity spectra of relevant seismic events, and the corresponding structural and hydrologic responses. 


\section{OVERVIEW}

This chapter summarizes the current understanding of nonisothermal flow and transport processes and phenomena related to high-level nuclear waste disposal in subsurface repositories. Also presented are research and experimental objectives related to providing data for evaluating conceptual and computer models used to estimate nonisothermal flow and transport related to performance assessment of environmental conditions surrounding the candidate repository site including the waste package environment. Specific hypotheses are proposed for evaluation using nonisothermal experiments and performance measures are identified for determining the appropriateness of identified hypotheses.

\subsection{Relevant Processes}

The processes which may affect nonisothermal flow and transport include thermal, liquid, solute, vapor, and gas movement, and thermo-mechanical effects (Childs and Malstaff, 1982; Pollock, 1986; Eaton et al., 1987). These processes can be described by coupled nonlinear partial differential equations (PDE's). Of special interest is the coupling between processes which causes complex interactions. The PDE's must be solved using theoretical or observed phenomenological coefficients. Some of the coefficients are highly nonlinear and hysteretic functions of fluid potential, water content, temperature and rock deformations. The general mass balance and constitutive relationship for uncoupled processes is:

$$
\nabla \cdot \mathrm{q}_{\mathrm{i}}=\nabla \cdot\left(\mathrm{K}_{\mathrm{i}} \nabla \phi_{\mathrm{i}}\right)=\mathrm{C}_{\mathrm{i}} \partial \Phi_{\mathrm{i}} / \partial \mathrm{t}+\mathrm{Q}_{\mathrm{i}}
$$

where

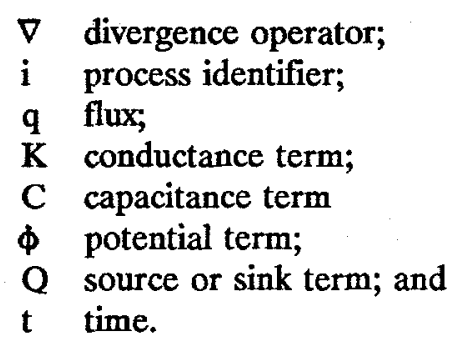

For fluxes which are coupled (i.e., a potential gradient in one process induces flux in a different process), the corresponding constitutive relationships are:

$$
\mathrm{q}_{\mathrm{i}}=-\boldsymbol{\Sigma} \mathrm{K}_{\mathrm{ij}} \nabla \Phi_{\mathrm{j}}
$$

The set of equations summarized by Equation (3.2) state that flux of species $i$ can be induced by a gradient of process $\mathrm{j}$ through the coupling term $\mathrm{K}$. Also, the capacitance and conductance terms for species $\mathrm{i}$ can be affected by the potential term for process $\mathrm{j}$ :

and

$$
C_{i}=f\left(\Phi_{j}\right)
$$

$$
\mathrm{K}_{\mathrm{i}}=\mathrm{f}\left(\phi_{\mathrm{j}}\right)
$$

Combining these equations yields a coupled processes relationship of the form:

$$
\left.\nabla \cdot R\left(\mathrm{~K}_{\mathrm{ij}}\left(\phi_{\mathrm{k}}\right) \nabla \phi_{\mathrm{j}}\right)\right]_{\mathrm{i}}=\mathrm{C}_{\mathrm{i}}\left(\phi_{\mathrm{k}}\right) \partial \phi_{\mathrm{i}} / \partial \mathrm{t}+\mathrm{Q}_{\mathrm{i}}
$$


TABLE 2: Processes, State Variables, and Selective Parameters

\begin{tabular}{|c|c|l||}
\hline Process & State Variable & \multicolumn{1}{|c|}{ Selective Parameters } \\
\hline Thermal & Temperature & $\begin{array}{l}\text { Thermal Conductivity } \\
\text { Heat Capacity }\end{array}$ \\
\hline Hydraulic & Pressure Head & $\begin{array}{l}\text { Hydraulic Conductivity } \\
\text { Characteristic Curve }\end{array}$ \\
\hline Pneumatic & Gas Pressure & $\begin{array}{l}\text { Air Permeability } \\
\text { Compressibility }\end{array}$ \\
\hline Vapor & Vapor Pressure & Vapor Diffusivity \\
\hline Mechanical & Deformation & $\begin{array}{l}\text { Shear Modulus } \\
\text { Compressibility }\end{array}$ \\
\hline Solute & $\begin{array}{r}\text { Ionic Strength } \\
\text { pH \& Redox State }\end{array}$ & Solute Diffusivity \\
\hline
\end{tabular}

A summary of the processes, state variables, and parameters of interest in this study are presented in Table 2. The table is not complete and is only presented to illustrate the relationship between processes, state variables and parameters. Many additional parameters, in particular, are required in order to fully characterize the identified processes. In some cases, the conductance and capacitance terms are combined into a single term, called the diffusivity, $\mathrm{D}_{\mathrm{i}}$ :

$$
D_{i}=K_{i} / C_{i}
$$

The parameters in the mass balance and constitutive relationships are a function of the geologic medium, the scale of observation, and the type of experiment. The parameters, also called phenomenological coefficients, can be estimated in the laboratory, using local field experiments, as well as by interpreting regional flow models. Estimates of the values of uncoupled phenomenological coefficients have been performed at the Apache Leap Tuff Site using laboratory and local field methods (Rasmussen et al., 1990).

The application of uncoupled flow and transport models to field investigations of thermohydrologic experiments is complicated by many factors, including (deMarsily, 1981; Evans, 1983; Rasmussen and Evans, 1987; Evans and Nicholson, 1987; Evans and Rasmussen, 1991):

- Nonlinear constitutive relationships;

- Heterogeneous parameters to represent material properties;

- Complex coupling between processes; and

- Difficulties in measuring parameters and state variables.

One approach for evaluating the various processes is to incrementally increase system complexity, from relatively uniform media with single processes, to more complicated systems with discrete subdomains and multiple processes. Experiments by Haldeman et al. (1991) and by Davies (1987) have demonstrated the capability to investigate isothermal flow and transport through unsaturated fractured rock, and nonisothermal flow and transport through unsaturated whole rock. Substantial uncertainties remain, however, related to coupling the multiple processes in more complicated experiments, presented as Table 3 . 
TABLE 3

Knowledge of Flow and Transport Processes

\section{Reasonably Well Understood}

- Heat conduction in saturated and unsaturated porous rock matrix

- Isothermal liquid flow in saturated and unsaturated porous rock matrix

- Conservative, isothermal solute transport of tracers in saturated rock matrix

More Difficult to Characterize and Describe

- Heat conduction in saturated and unsaturated fractured rock

- Isothermal liquid flow through saturated, fractured rock

- Isothermal gas flow through dry fractured rocks

- Isothermal gas flow through variably saturated rock matrix

\section{Even Less is Known}

- Heat transport by conduction and convection in heterogeneous saturated porous media and in homogeneous variably saturated porous media

- Isothermal fluid flow through partially saturated fractured porous rocks

- Conservative isothermal solute transport of tracers in saturated fractured rock

\section{Very Little is Known}

- Heat conduction and convection coupled with multiphase fluid flow in nonuniform porous media

- Nonisothermal liquid flow through partially saturated fractured porous rocks

- Nonisothermal gas flow through partially saturated fractured porous rocks

- Conservative solute transport of tracers in unsaturated fractured rock

\section{Nothing is Known}

- Heat conduction and convection coupled with multiphase fluid flow in fractured porous media

- Multiphase fluid and solute transport through nonuniform porous and fractured rocks at temperatures above the boiling point 


\subsection{Conceptual Model}

HLW generates significant thermal energy which decreases over time. The thermal energy should affect the rock matrix by causing physical deformation of the rock due to thermal expansion, as well as by driving water as vapor away from the region surrounding the thermal source. Thermal stresses should cause rock deformation and displacements within the rock mass and across fractures. Liquid water and entrained solutes may move toward the thermal source in response to a matric potential gradient.

Thermal influences including thermo-mechanical effects and heat transport should combine with capillary and gravity forces to alter the distribution and transport of water, gas, and solutes. As the temperature of the formation increases near a heat source, the gas pressure should increase causing a pressure gradient away from the heat source. Various computer simulation studies (Cullinan, 1983; Pruess et al. 1990) have focused on the complex roles of fractures and rock matrix near a heat source. As the temperature approaches $100^{\circ} \mathrm{C}$ the water vapor generated in the rock matrix flows towards fractures and then away from the source, eventually condensing on fracture walls in a cooler region. The condensate either moves within the fracture or into the rock matrix. If the liquid is sufficiently mobile the condensate may flow toward the heat source and cause a countercurrent to form with temperatures near $100^{\circ} \mathrm{C}$. If the liquid is not sufficiently mobile, then the countercurrent may not form and the region of desiccation may expand outward inducing substantially higher temperatures. A well-defined circulation cell may also be obscured if the countercurrent is too active.

Transport of solutes may be affected by their ionic charge, with ions of various charges moving differentially due to cation exchange effects, solubility, volatilization, and ion-exclusion. The effect of elevated temperatures and carbon dioxide removal due to a net outward movement of gasses may affect the solubility of various mineral species. The migration of various natural or induced tracers in response to changing thermohydrologic conditions is vital for understanding the waste containment capability of the candidate HLW site.

Mechanical conditions at a candidate site should be altered by the thermal impacts of waste emplacement, as well as by mining of the shafts and drifts. Analysis of the thermo-mechanical and mining-induced displacements and deformations are complicated by fractures and other discontinuities. Thermomechanical impacts may be greatest near the canister, yet changes in stress and strain regimes may be observable over large regions. Displacements along fractures may affect the fluid transport properties of the fractures, either to enhance or impede fluid movement. Deformation of the rock matrix may not have as significant an impact on the hydraulic properties as fracture displacement.

Predictions based on simulation modeling activities must be tempered by observations. Experience from laboratory experiments indicate a number of important phenomena which substantially affect fluid flow and solute transport. Laboratory experimental results indicate:

- Latent heat transport in the vapor phase, with sensible heat transport in the solid, liquid, and gas phases (Davies, 1987);

- A strong heat-pipe effect arising from countercurrent liquid-vapor flows which causes desiccation near the heat source and a concomitant accumulation of water away from the source (Davies, 1987);

- The possibility for osmotic potential to reduce the magnitude of the heat-pipe effect due to solute concentration effects on osmotic potential vapor pressure reduction near the heater; and

- The dissolution and precipitation of minerals in fractures which can alter the physical properties of the bulk rock (Lin, 1991).

These laboratory findings must be balanced by experimental evidence conducted over field scales using less artificial boundary conditions. The field scale findings include: 
- Heat transport occurs from the source as sensible and latent heat, causing a desiccation of the rock near the source which expands over time (Davies, 1987);

- Liquid water accumulates in boreholes and openings near the heat source, with little water accumulation in the densely welded tuff matrix (Davies, 1987); and

- Substantial air movement occurs through fracture networks due to orographic and barometric gradients (Smith, 1989).

The engineered portion of the waste-repository structure should undoubtedly affect the thermohydrologic regime as well. The placement of shafts, seals, drifts, boreholes, ventilation ducts, and drains, as well as the waste form and encasement, should have an impact on fluid flow and solute transport. It can be inferred that the operation of a ventilation system should affect the transport in the vapor phase by:

- The injection of dry exterior air which will be circulated through the open repository;

- The resultant transport of water through the repository as vapor;

- The discharge of humid air to the atmosphere; and

- The alteration of the existing orographic and barometric circulation within the subsurface.

By circulating air through the repository, substantial quantities of water should be removed and discharged to the atmosphere, thus causing the desiccation and cooling of interior repository surfaces. For isolated chambers within the repository, substantial condensation may or may not occur depending upon the moisture and thermal gradients across the chamber. Also, substantial condensation may occur in the exhaust system.

Two distinct thermal phases will be observed during the field experiment, a heating phase and a cooling phase. The proposed experiment should try to reproduce the HLW-imposed effects by reproducing the two thermal phases; a heating phase during which a heat source will be used to generate nonisothermal conditions in unsaturated fractured tuff at Apache Leap; and a cooling phase in which the heat which has accumulated near the heater is allowed to dissipate. The following two subsection describe the expected conditions during the two phases.

\section{Heating Phase}

During the heating phase, liquid water immediately around the heat source should vaporize in response to an increase in the vapor pressure deficit. The vapor should move to zones further away from the heat source due to pressure gradients and diffusion, forming a zone of desiccation. The outward vapor flow should be greater in undrained fractures than in the matrix due to higher pneumatic permeabilities of the fractures. The fracture permeabilities should also be affected by changes in rock mechanical displacement and deformation due to thermal expansion. Heat flux away from the source should occur as sensible heat conduction and latent heat transfer in the vapor phase. As the temperature decreases away from the heat source, the vapor should condense within fractures and the matrix at some distance from the heat source, forming a zone of liquid water accumulation. The liquid water in the zone of accumulation may move in various directions:

- Towards the zone of desiccation due to a liquid potential gradient;

- Towards the domain boundaries, also due to a potential gradient; and

- Vertically downward due to gravitational forces.

Below the heat source, the upward flow of liquid water towards the zone of desiccation should be small, with accumulated water draining downward through vertical fractures due to gravitational forces. Within the horizontal plane of the heat source, net liquid water flow should be downward, away from the heat source through gravity drainage in vertical fractures. It is hypothesized that the largest zone of accumulation will be found above the zone of desiccation. If this is the case, then liquid flow should occur back toward the heat source in fractures, and may reach the heat source, depending upon many factors, including: 
- The strength and horizontal extent of the heating source;

- The downward rate of natural deep percolation from above;

- The magnitude of fracture and matrix permeabilities;

- The initial rock water content;

- The rock thermal conductivity; and

- The magnitude of free convection.

It is also possible that water under positive pressures will accumulate in existing cavities due to large temperature and vapor pressure gradients across the cavity. Water vapor may enter the cavity on a surface nearer the heater, diffuse across the cavity in the vapor phase, and condense on a cooler surface on a farther wall. The condensation may result in sufficient liquid accumulation so that the water will be under atmospheric or positive pressure. Free water drainage would then occur within the cavity and either accumulate at the lower end of the cavity, or drain through fractures intersecting the accumulated free water.

\section{Cooling Phase}

Once the heat source has been removed, rock temperatures should decrease over time due to conduction of heat through the rock as well as the outward convection of air. The vaporization of liquid water should decrease and vapor phase transport should diminish, except along the boundary between the zones of desiccation and accumulation where the greatest temperature gradients may be found. During this phase, vapor redistribution should predominate with the greatest redistribution occurring between the zones of desiccation and accumulation above the heat source; the invasion rate being greatest from above the thermal source. The initial drainage through fractures from the zone of accumulation should occur quickly, while redistribution of rock matrix water in the vapor phase should occur at a slower rate. Higher water transport rates in the vapor phase as compared to liquid phase movement should cause a much longer resaturation period when compared to the initial drying phase.

\subsection{Constraints}

Various constraints limit the capability to identify and evaluate the conceptual model described earlier. Various types of experimental constraints can be identified, including:

- Technological methodologies for estimating material properties at the scale of interest. (Examples include fluid, solute, and heat transport parameters for flow along and across discrete fractures, and the three-dimensional rock deformation variation)

- Conceptual methodologies for aggregating local estimates of material properties into bulk properties at larger scales (i.e., upscaling). (An example would be the estimation of fluid, solute, and heat flow through networks of fractures embedded in porous rock.)

- Technological methodologies for obtaining information about state variables. (Examples include the measurement of matric potentials in rocks and fractures, liquid water contents in fractures, and liquid water chemistry in rocks and fractures.)

- Conceptual and computational methodologies for coupling strongly nonlinear, hysteretic functions. (Examples include the estimation of fluid and thermal fluxes through fractured rock with large temperature and fluid pressure gradients.)

\subsection{Objectives}

The primary objective of performance assessment is to evaluate the ability of an engineered facility and geologic environment to contain and isolate HLW. An important requirement related to the geologic environment is the demonstration of the ability to reliably predict fluid flow and solute transport through nonisothermal, unsaturated, fractured rock under field conditions using the mass balance and constitutive relationships presented elsewhere in this document. 
The general objective of nonisothermal experiments is to monitor the response of a geologic system to a thermal source, and to adequately explain the observed behavior using nonlinear, coupled, heterogeneous constitutive and mass-balance relationships. This general objective can be divided further into more specific, although still general, subobjectives:

- To further assess appropriate methods, techniques and technologies for characterizing and monitoring fluid flow, solute transport and thermo-mechanical changes in unsaturated fractured rock, including interaction between the rock matrix and the fracture system;

- To examine relevant hydraulic, pneumatic, solute and thermal transport and thermo-mechanical processes and relevant parameters, singularly and coupled, at field scales up to five meters;

- To evaluate the thermomechanical effects of a heat source on fracture and matrix pneumatic and hydraulic transport properties;

- To generate data for complex, coupled flow and transport systems for use in the evaluation of unsaturated flow and transport models; and

- To assess various modeling approaches and their limitations in predicting flow and transport through nonisothermal, unsaturated, fractured rock.

These objectives are related to the assessment of the suitability of existing conceptual and computational models which represent the hydraulic, pneumatic, thermal, solute transport and thermo-mechanical properties and processes in fractured rock. The objectives incorporate the predictive ability of various alternative modeling strategies for their ability to accurately represent fluid flow and solute transport processes in unsaturated fractured rock. Yeh et al. (1988) discuss the various conceptual models being considered along with a review of numerical codes for providing simulation results prior to performing the experiments.

The identified objectives and subobjectives are designed to be generic in nature, that is, they are suitable for application by other researchers at other sites in any particular geologic environment. While the emphasis may change from site to site due to local conditions, the above objectives are generally appropriate for guiding a wide-variety of nonisothermal studies in unsaturated, fractured rock.

\subsection{Hypotheses}

The conceptual models described above depend upon specific hypothesized phenomena, listed below.

- A saturated zone within the host rock around the heat source. From modeling studies and limited laboratory and field studies, it can be hypothesized that rising temperature near the repository will induce vapor diffusion away from the repository and produce dry zones in and around the heater, and wet zones away from the heater. (Pruess et al., 1990)

- The largest zone of water accumulation may be found above the zone of desiccation. (Buscheck and Nitao, 1990)

- If fractures are present, then preferential drying should occur near the heater in the rock matrix near the fractures. Further away, the fractures should become saturated due to condensation. (Cullinan, 1983)

- Heat transport primarily by conduction, except for limited regions of significant latent heat transport. (Pruess, 1991)

- Countercurrent flow conditions (i.e., the heat pipe phenomenon) within the host rock near the heat source. (Doughty and Pruess, 1988)

- Anaerobic atmospheric conditions may exist near the heat source, with the air phase completely replaced by water vapor. (Buscheck and Nitao, 1990) 


\subsection{Performance Measures}

A performance measure is specified which can be used to determine whether a postulated phenomenon can be confirmed or rejected. Model performance evaluation utilizes estimates of system response in conjunction with model forecasts. System responses to changes in system boundary conditions manifest themselves by changes in state variables within the system.

For many systems the state variables may not be constant as a function of position or time. This variation can be called the system response variation. Measurements of system state variables may not be precise or accurate due to inherent limitations in the measurement device. The device may have a limited range of measurement, or be biased within the range of measurement. This type of error can be called measurement error. Another error is introduced when a model incorporates inappropriate physical processes or constitutive relationships. This type of error can be called model specification error.

Of interest to model evaluation is the ability of the model forecast to reliably reproduce the system response. The difference between the forecast and the observed response is the forecast error. The forecast error is estimated using:

$$
e_{f}=x_{s}-x_{m}
$$

where

$$
\begin{aligned}
& e_{f} \text { forecast error, } \\
& x_{s} \text { predicted system response, and } \\
& x_{m} \text { measured system response. }
\end{aligned}
$$

The sample variance of the forecast error, $\mathrm{s}_{\mathrm{f}}^{2}$, is estimated using:

$$
s_{\mathrm{f}}^{2}=E\left[\mathrm{e}_{\mathrm{f}}^{2}\right]
$$

Also, the population variance of the forecast error can be estimated by assuming independence between errors, which leads to:

$$
\sigma_{\mathrm{f}}^{2}=\mathrm{E}\left[\mathrm{s}_{\mathrm{f}}^{2}\right]=\sigma_{\mathrm{r}}^{2}+\sigma_{\mathrm{m}}^{2}+\sigma_{\mathrm{s}}^{2}
$$

where

$\sigma_{f_{2}}^{2} \quad$ variance of the forecast error,

$\sigma_{\mathrm{r}_{2}}$ variance of the observed system responses,

$\sigma_{\mathrm{m}}{ }^{2}$ variance due to measurement errors, and

$\sigma_{s}$ variance due to model specification errors.

Model performance can be tested using two techniques:

- By evaluating whether the predicted system response is unbiased (i.e., $\mathrm{E}\left[\mathrm{e}_{\mathrm{f}}\right]=0$ ); and

- By evaluating whether the variance of the forecast error is equal to the sum of the measurement plus system variability errors (i.e., $\sigma_{s}^{2}=0$ ).

Rigorous statistical tests can be performed if the distribution of errors can be determined. The variation due to measurement error can be estimated using repetitive and duplicative measurements. The observed system response variation can be estimated given sufficient monitoring information. The forecast error can be obtained using Monte Carlo or theoretical estimates of predicted system responses. 


\section{EXPERIMENTAL APPROACH}

This chapter presents a field experimental approach for examining thermohydrologic processes in unsaturated, fractured rock. To demonstrate and evaluate the proposed methodology, a nonisothermal experiment is proposed at the Apache Leap Tuff Site, near Superior, Arizona. This chapter describes the phases and tasks required for conducting such an experiment, along with simulation modeling and site characterization required prior to implementing the experiment.

\subsection{Study Phases and Tasks}

Six study phases have been identified that provide data useful for the evaluation of conceptual and computer models related to nonisothermal hydrologic transport in unsaturated fracture rock. Table 4 presents the six study phases which may be employed for studies related to the objectives described above. The study phases are generic in nature and can be applied to any site, within the limits of the study objectives. Figure 4 presents a logic diagram for the experimental studies. Three separate experiments are proposed which consist of activities conducted partly in series and partly in parallel to each other. The first two experiments are preliminary experiments which are to be conducted in parallel to each other, as described in Chapter 5. Following the completion of the preliminary experiments, the full-scale heater experiment can be conducted. Each of the experiments incorporate the phases described below.

The first phase identified in Table 4 consists of computer modeling activities related to the determination of an initial experimental design. The simulation studies should use existing characterization data from nearby sites, if available. Design issues related to borehole construction and monitoring techniques are examined during Phase 1. Phase 2 activities focus on installation of boreholes based on Phase 1 simulation studies. Additional site-specific characterization data are obtained using information from the initial borehole installation, including borehole logs, borehole permeability tests, and laboratory characterization tests using oriented cores. Monitoring of moisture and thermal conditions begin during this phase. During Phase 3, additional simulation modeling is employed using the site-specific characterization data collected in Phase 2. The simulations should be used to refine the placement of sensors, the heater, packers and isolation facilities such as bulkheads or a surface cover. After completion of the simulation studies, the placement of the instruments and other components should be performed.

Phase 4 consists of baseline data collection at the site from the sensors placed during Phase 3 . The baseline data are used to determine the initial and boundary conditions as input to computer simulation models for the purpose of determining the optimal heater schedule. Phase 5 consists of generating simulation forecasts and confidence intervals for the heater experiment, and conducting the heating experiment. The two components should be conducted independently and without any cross-communication between the two. Field data should be collected, processed and archived until such time as the simulation studies have been completed. The only exception to this rule should be if there are changes in boundary conditions or if additional characterization data become available.

Simulation results should be compared with experimental results during Phase 6. The performance of the simulation models should be evaluated based on their ability to predict field observations. No calibration against the experimental results is expected, and the comparisons should be a test of model accuracy. Confidence intervals should be inspected to determine if the model projections include the observed range of system responses. The forecasts are then used to evaluate alternate models. The phases can be divided into specific tasks, presented as Table 5. The tasks are organized by phase, and each task has a specific activity associated with it. While details related to each task are not elucidated in this document, it is expected that procedures should be developed to implement each of the tasks. 
TABLE 4

\section{Nonisothermal Hydrologic Transport Study}

\begin{tabular}{|c|l|}
\hline Phase 1 & $\begin{array}{l}\text { Perform simulations using existing characterization data from the nearby Apache } \\
\text { Leap injection site for the purpose of obtaining a preliminary experimental design. } \\
\text { Evaluate alternate characterization and monitoring techniques at the injection site. } \\
\text { Issues such as borehole locations, orientations and drilling methods should be } \\
\text { resolved during this phase. }\end{array}$ \\
\hline Phase 2 & $\begin{array}{l}\text { Install boreholes and further characterize the heater site using in situ and labo- } \\
\text { ratory core measurements. Obtain in situ conditions for water contents and tem- } \\
\text { peratures. Select and calibrate measurement devices. }\end{array}$ \\
\hline Phase 3 & $\begin{array}{l}\text { Refine the experimental design based on data collected in Phase 2 and additional } \\
\text { simulation studies. Using this information, install sensors, heater, packers and } \\
\text { surface cover. Also, install additional boreholes if needed. }\end{array}$ \\
\hline Phase 4 & $\begin{array}{l}\text { Collect baseline data from sensors installed in Phase 3, and continue monitoring } \\
\text { water contents which were started in Phase 2. Use data in conjunction with } \\
\text { computer modeling activities to refine heating schedule. }\end{array}$ \\
\hline Phase 5 & $\begin{array}{l}\text { Perform heater test and measure responses. Concurrently and independently } \\
\text { simulate responses using baseline and characterization data, as well as observed } \\
\text { initial and boundary conditions. }\end{array}$ \\
\hline Phase 6 & $\begin{array}{l}\text { Compare experimental and simulation results. Determine whether the observed } \\
\text { response lies within forecasted confidence intervals. Obtain and test core samples } \\
\text { to confirm final conclusions. }\end{array}$ \\
\hline
\end{tabular}




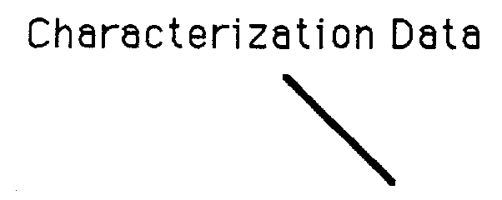

Preliminary Experimental Design

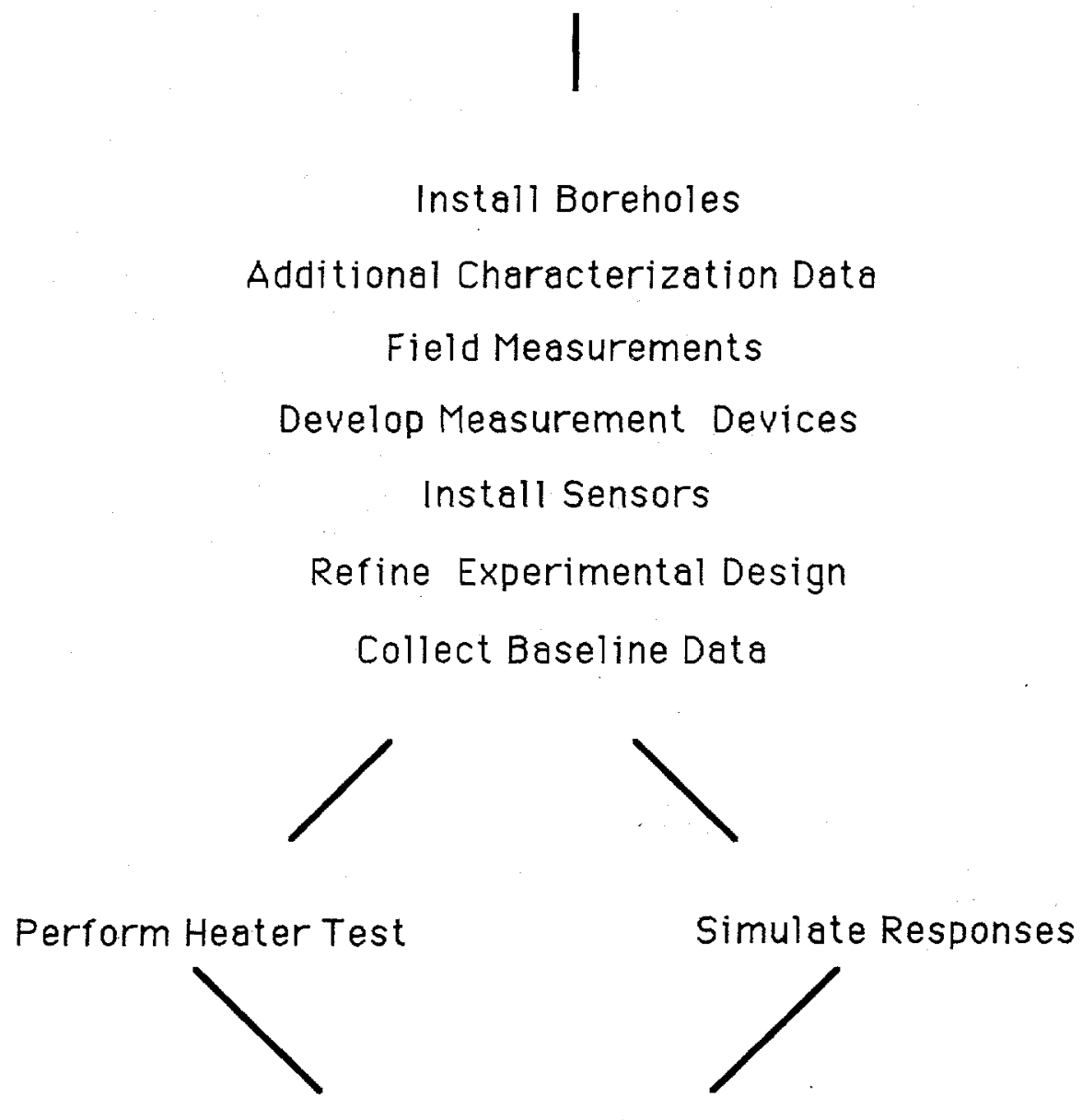

Compare Experimental and Simulation Results

Figure 4: Logic diagram for field heater experiments 


\section{TABLE 5}

Experimental Tasks for Nonisothermal Experiment

\section{Phase 1}

Task 1: Select a simulation model, or models, appropriate for nonisothermal processes in unsaturated, fractured rock.

Task 2: Assign material properties using existing data from the site or from nearby sites.

Task 3: Assign initial and boundary conditions based upon data from the site or from nearby sites.

Task 4: Perform simulations to determine the response of the rock unit at the heater site to alternate heating and cooling scenarios.

Task 5: Estimate an appropriate orientation and depth of the heater and observation boreholes.

\section{Phase 2}

Task 6: Install boreholes using techniques that minimize disturbances and provide oriented core.

Task 7: Perform laboratory characterization tests on the core segments.

Task 8: Perform field characterization tests in the boreholes

Task 9: Obtain preliminary baseline data using neutron probe, temperature probes, and geophysical scanning of the boreholes.

Task 10: Determine boundary conditions appropriate for the liquid, gas, vapor, and solute phases, and for temperature.

Task 11: Acquire and calibrate sensors, meters, and data collection system. Determine the capacity and reliability of the heater and power source.

Phase 3

Task 12: Redo Tasks 4 and 5 using material properties, and initial and boundary conditions obtained from Phase 2 activities.

Task 13: Based on results from Task 12, install heater, packers, sensors and cover. Add final access holes as needed. 
Phase 4

Task 14: Begin continuous basefine monitoring using sensors installed in Task 13.

Task 15: Using baseline data from Task 14, redo simulation modeling to determine optimal boundary conditions and heating schedule.

\section{Phase 5}

Task 16: Based on simulation results obtained in Task 15, begin heater operation. Operate heater at increasing output levels.

Task 17: Monitor system responses to Task 16.

Task 18: Prepare simulation forecasts of system response to heater operation. Include forecast errors, uncertainty estimates, and confidence intervals. This task should be performed in ignorance of Task 17 for the power output level being evaluated, but can include information obtained from Task 16 if there are changes in boundary conditions or if additional characterization data become available.

\section{Phase 6}

Task 19: Compare simulation results of Task 18 to experimental results obtained in Task 17. Determine the accuracy of the prediction. Obtain core samples to confirm measurement and model predictions.

Task 20: Convene workshop to evaluate results and to determine additional information needs.

\subsection{Simulation Modeling}

Simulation modeling should be employed during the project for several purposes. One simulation requirement is to determine the experimental design which optimally discriminates between alternate conceptual models of nonisothermal flow through unsaturated fracture rock. Prior to conducting the experiment various conceptual models are proposed and simulation models constructed in order to predict the outcomes for each of the models. If the model responses are identical for a particular experiment, then the experiment will fail to determine which of the conceptual models is more appropriate. Thus, the experimental conditions will need to be modified until unique responses are observed for the various conceptual models (Rasmussen, 1986).

Another simulation requirement is to accurately predict the observed outcome. Ashworth and Ashworth (1984) present an application of laboratory and field measurements to confirm model forecasts. Using this strategy, independence between model simulation activities and experimental observations should be required. If the model is updated to incorporate additional processes or material properties, then the exercise only serves as model calibration. To successfully evaluate the model, prediction requires prior 
forecasts of the experimental outcome. Because some uncertainty should exist in the forecasts, confidence intervals about the forecast must be constructed. The performance measure can be numerical or heuristic.

Previous laboratory, field and laboratory isothermal and nonisothermal experiments at the University of Arizona have demonstrated the complexity associated with fluid flow in unsaturated fractured rock (Huang and Evans, 1985; Green and Evans, 1985, 1987; Green et al., 1987; Rasmussen et al., 1985; Schrauf and Evans, 1986; Evans et al., 1987; Rasmussen, 1987a; Weber and Evans (1988); Rasmussen et al., 1988; Rasmussen and Evans, 1989; Rasmussen et al., 1989). To avoid ambiguous and inconclusive experimental results it is important that simulation modeling and site characterization be performed prior to conducting the field experiment.

Simulation modeling should be employed to identify the important features of the experiment including zones of saturation, regions where fracture flows are expected, accumulation of high salinity waters near the evaporation front, and changes in rock deformation and displacement near the heater source. The effects of gravity, fracture properties, initial water saturation, initial solute concentration, and material heterogeneities should be examined using sensitivity analyses. The types and locations of sensors to be installed should also be examined to determine the required sensor sensitivities and the regions where the greatest changes are expected. Knowledge of the types of monitoring equipment to install, where to place the monitoring equipment, and where and how the heater should be placed and operated requires that the simulation model incorporate all relevant processes as well as realistic parameters.

\subsection{Site Characterization}

Simulation models require that estimates of material properties and boundary and initial conditions be obtained for the site of interest. Material properties for use in simulation models have been obtained from the Apache Leap Tuff injection site. The Apache Leap Tuff Site is located in the Apache Leap Tuff Formation (dated approximately 19 million years) immediately east of Superior, Arizona, approximately 160 $\mathrm{km}$ north of Tucson, and $100 \mathrm{~km}$ east of Phoenix. The rocks exposed at the site are the uppermost unit of a sequence of ash-flow tuff sheets. The tuff formation grades from a densely welded unit near its base to a slightly welded tuff at the top. The tuff is a consolidated deposit of volcanic ash, with particle diameters less than $0.4 \mathrm{~mm}$, resulting from a turbulent mixture of gas and pyroclastic materials of high temperature. The ash-flow deposits at one time covered an area of approximately $1000 \mathrm{~km}^{2}$ with a maximum thickness of $600 \mathrm{~m}$ but have been eroded in some places to about $150 \mathrm{~m}$ in thickness (Peterson, 1961). At the heater site, the tuff thickness is approximately $500 \mathrm{~m}$. The unsaturated zone extends to great depth at the site due to topography and to groundwater pumping associated with a nearby underground mine. Fracture traces are evident on the land surface and can extend horizontally for several hundred meters.

Atmospheric precipitation has been recorded near the heater site, with the long-term average estimated to be $538 \mathrm{~mm} \mathrm{yr}^{-1}$. Most of the precipitation occurs during two periods, from mid-July to late-September, and from mid-November to late-March. Summer storms are characterized by high-intensity, short-duration thunderstorms during periods of high temperature and evapotranspiration demand. Winter storms are of longer duration and lower intensity during cooler periods with much lower evapotranspiration demand.

\section{Available Material Properties}

Laboratory experiments and measurements have been conducted using cores obtained during borehole drilling at the injection site and using shaped blocks removed near the field site. Characterization data are available for the interstitial, hydraulic, pneumatic and thermal properties of the rock matrix, as well as geometrical, hydraulic, pneumatic, and thermal properties of the bulk rock. Laboratory experiments have been used to characterize the unsaturated hydraulic and pneumatic properties of discrete fractures embedded in porous tuff blocks (Rasmussen et al., 1990; Chuang et al., 1990; Rasmussen, 1991; Haldeman et al., 1991). 
Characterization parameters for core segments of three sizes collected at approximately three meter intervals from nine boreholes have been estimated for 105 samples. Field parameters were obtained at the same three meter interval centered on the position where the core segments were collected. Data obtained from field and laboratory tests are of the following types:

- Rock matrix interstitial properties, consisting of bulk and skeletal densities, effective porosity, pore surface area, and pore size distributions collected from the core segments;

- Rock fracture interstitial properties, consisting of fracture location, density, and orientation, collected from oriented cores;

- Rock matrix hydraulic properties, consisting of the laboratory saturated hydraulic conductivity, moisture characteristic curves, and unsaturated hydraulic conductivity curves collected from core segments, as well as field saturated hydraulic conductivity determined from borehole interval testing;

- Water content dependent pneumatic permeability of unfractured rock cores for a range of water contents, as well as the air permeability of fractured rock at ambient water contents at the injection site;

- Water content dependent electrical resistivity properties of unfractured rock core segments; and

- Water content dependent thermal conductivity and specific heat of unfractured rock core segments.

Summary data are presented in Rasmussen et al. (1990) for the parameters, including the mean, coefficient of variation, minimum, median and maximum values. The data were collected either from 105 core segments located at approximately three meter intervals, or from borehole test intervals which test three meter intervals coincident with the core segment locations. For the 105 samples tested, bulk densities of the largest segments lie between 1.86 and $2.20 \mathrm{~g} \mathrm{~cm}^{-3}$, with an arithmetic average of $2.10 \mathrm{~g} \mathrm{~cm}^{-3}$ and a coefficient of variation of $3 \%$. The effective porosity of the largest segments ranges between 14.30 and 27.51 percent volumetric, with a mean of 17.54 percent and a variation of $13 \%$. Mean skeletal density is $2.55 \mathrm{~g} \mathrm{~cm}^{-3}$ with a variation of $2 \%$. Mean pore area of the medium sized segments is $3.466 \mathrm{~m}^{2} \mathrm{gm}^{-1}$ with a variation of $65 \%$. For the 105 borehole intervals examined, the fracture density ranged from 0 to 4.33 fractures per meter, with a mean of 0.77 and a coefficient of variation of 108 percent.

The relative saturation of rock core segments decreases from a mean of 95.5 percent at $10 \mathrm{kPa}$, to 70.2 percent at $100 \mathrm{kPa}$, to 47.5 percent at $1000 \mathrm{kPa}$, to 22.2 percent at $10,000 \mathrm{kPa}$, to 12.8 percent at 100,000 $\mathrm{kPa}$. Results of hydraulic testing of core segments indicate a mean saturated hydraulic conductivity of 21.31 $\times 10^{-9} \mathrm{~m} \mathrm{~s}^{-1}$ with a coefficient of variation of $301 \%$ and a range of approximately three orders of magnitude. The unsaturated hydraulic conductivity means at $10,25,50$ and $100 \mathrm{kPa}$ are $3.346,1.475,0.908$, and 0.364 $\times 10^{-9} \mathrm{~m} \mathrm{~s}^{-1}$, respectively. Field estimates of saturated hydraulic conductivity range from a mean of 29.19 to $59.42 \times 10^{-9} \mathrm{~m} \mathrm{~s}^{-1}$ depending upon the method used to interpret the field tests. The variation of the field estimate is approximately $700 \%$ and ranges over five orders of magnitude. Field water contents are estimated using neutron count data calibrated in the field at two locations with different water contents. Field water contents range from a low of 9.53 percent to a high of 18.75 percent on different dates.

Data for core segments yield an oven-dried air permeability of $57.12 \times 10^{-16} \mathrm{~m}^{2}$, decreasing to half that value at approximately $100 \mathrm{kPa}$. The laboratory measurements of air permeability display great variability, ranging over three orders of magnitude with a coefficient of variation of $272 \%$. A difference between air and water permeability is explained by the Klinkenberg effect. Measured field air permeabilities are generally less than measurements obtained from oven-dried core segments.

A mean saturated thermal conductivity of $1.821 \mathrm{~W} \mathrm{~m}^{-1}{ }^{\circ} \mathrm{C}^{-1}$ is observed for large core segments, with a

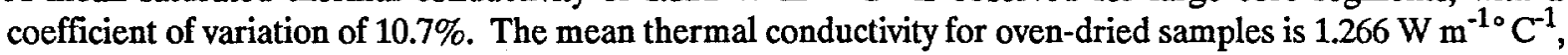
with a coefficient of variation of $11.5 \%$. For the thermal conductivity parameter, the influence of relative saturation is substantially less than for the hydraulic conductivity. A thermal conductivity of $1.95 \mathrm{~W} \mathrm{~m}^{-1}{ }^{\circ} \mathrm{C}^{-1}$ and a heat capacity of $2.4 \times 10^{6} \mathrm{~J} \mathrm{~m}^{-3 \circ} \mathrm{C}^{-1}$ provide a good fit to field observations of thermal responses to an annual thermal cycle. 
Thornburg (1990) determined the empirical parameters of the Archie equation for selected Apache Leap injection site rock core samples using dilute, high resistivity pore waters. The exponent of the porosity term $(m=2.13)$ compares favorably with values determined for cemented sedimentary and volcanic rocks. However, the exponent of the water saturation term $(n=0.67)$ is anomalously low as compared to other common geologic media.

Apparent resistivity profiles obtained by Thornburg (1990) were collected using a Wenner array in the field at electrode spacings of 0.9 and 1.8 meters. Laboratory resistivity values ranged from 50 to $250 \mathrm{ohm}$-meters, but field measurements locally reached values greater than $500 \mathrm{ohm}$-meters where drained fractures apparently interrupted the flow of electrical current. Field resistivities responded primarily to moisture distributions which were controlled by:

- North- and northwest-striking fracture zones;

- Topographic features such as depressions and ridges;

- Depth below surface; and

- Seasonal precipitation and temperature profiles.

Electrical resistivity measurements were also obtained prior to and following precipitation events. Results indicate substantial changes in electrical properties following precipitation events, but interpretation of the electrical resistivity changes is complicated by concomitant temperature changes which also affects measured resistivity values. In fact, the reduction in temperature due to the precipitation event caused a greater change in resistivity than the expected change due to wetting of the rock from rainfall. The observed resistivity increased after the rainstorm event, in spite of the expected higher rock matrix water content.

\section{Initial Conditions}

The ambient field conditions prior to the heater experiments should be determined using long-term data. Field measurements of water content and temperature distributions have been obtained at the injection site to a depth of $30 \mathrm{~m}$ over several annual cycles. The time series of field borehole water contents are derived from neutron count measurements and the time series of field borehole temperature are measured using thermistor strings. Temperatures below approximately $10 \mathrm{~m}$ appear to be nearly constant over time with only a small geothermal gradient of $0.03 \mathrm{C} \mathrm{m}^{-1}$, while water contents appear to remain relatively unaffected below the surface.

One component of the experimental design should be to determine the preferred drilling technique (dry or wet) for the purpose of evaluating the effect on the initial conditions. Wet drilling may result in localized zones of saturation near the boreholes, while dry drilling may desiccate the rock formation. Extended monitoring within the drilled boreholes may have to be performed prior to beginning the heater test. It is proposed that monitoring boreholes be installed at various locations near the heater site. The boreholes would be used to monitor initial conditions and to provide information on environmental transients which may affect the interpretation of the heater test. The boreholes could be drilled using wet or dry drilling techniques, or pneumatic percussion methods could be used to minimize water content changes in the host rock. High-resolution neutron logs of water content should be obtained in the monitoring holes, along with high-resolution measurements of rock wall temperature.

\section{Boundary Conditions}

The determination of the upper boundary condition may critically affect test interpretation. Whether variable temperatures, water contents and barometric pressures are assumed, as opposed to constant values, is an important question which should be resolved by obtaining measurements of environmental conditions. One design possibility is to cover the heater site with an impermeable, insulating surface to inhibit water and thermal flux through the upper surface of the rock mass. Either a large tent maintained over the site, or 
a paved surface immediately in contact with the rock are possible alternatives. Regardless of whether or not a cover is used, the monitoring boreholes described in the previous section should be used to monitor changes in the upper boundary condition which may affect heater test interpretation.

The lower and outer boundary conditions may be less significant in terms of their variability and impacts on test interpretation than the upper boundary condition. Measurements of the lower and outer boundary conditions will be required in order to assign meaningful values in computer simulation models. The monitoring boreholes would be employed to determine the lower and outer boundary conditions before, during and after the test. Estimation of the effects of natural gas flow and attendant moisture transport due to barometric and temperature changes have been studied by Smith (1989). The study demonstrated the importance of monitoring gas movement and temperatures in large discrete fractures to determine the magnitude and direction of air flow.

\section{Additional Data Requirements}

The parameters currently available from the Apache Leap Tuff Site can be used to provide initial estimates of parameters for use in prototype simulations of the heater experiment. Material properties obtained from characterization data at the Apache Leap injection site are probably representative of conditions at the heater site, given their close proximity and similar geologic strata.

As additional site-specific information becomes available from the heater site, then updated simulation should be performed. Important additional site-specific characterization parameters include: unsaturated hydraulic, pneumatic, and thermal conductivities; air, vapor and solute diffusivities; vapor pressure reduction due to osmotic potential; and wetting and drying diffusivities. Characterization data should be obtained using field tests of high resolution, such as air permeability tests at close spacings in boreholes installed at the heater site, or using laboratory core samples collected nearby. Methods to be utilized are presented in Kilbury et al. (1986), Rasmussen (1987b), Tidwell et al. (1988), and Rasmussen et al. (1990). Convective heat transport through fractures may or may not be possible to measure. The determination of thermal anomalies in and around fracture zones may be possible to identify, however. Alternate sampling strategies to observe and monitor convective heat transfer may need to be developed. Procedures by Ashworth and Ashworth (1990) may also be applied.

Measurements of electrical resistivity could be employed to monitor changes in water content and solute concentration. In a nonisothermal environment, however, the temperature effects on electrical resistivity should overwhelm any changes in rock water content or chemistry (Thornburg, 1990). Electric permittivity measurements are less susceptible to temperature variation, however, and may provide better estimates of water content changes. Means to estimate water chemistry changes using noninvasive methods are lacking, however. Estimates of ionic strength, $\mathrm{pH}$, and redox state are difficult, if not impossible, to obtain in unsaturated, fractured rock, and nonintrusive techniques to obtain measurements of this kind are critical for understanding solute transport behavior. Sampling of water quality may be possible using destructive methods, where a core is obtained and the fluid is forcibly removed. Chemical alteration may still be unavoidable, however, using destructive sampling techniques. Mineral chemistry before and after the test is possible by using petrographic, $x$-ray diffraction, and chemical analyses of the minerals and glass in the rock. This analysis could possibly identify important chemical reactions resulting from the fluid and heat transfer processes. Obtaining data related to solute and tracer movement are limited by several important issues, such as whether tracers exist that do not disturb the existing flow field, and whether natural tracers may exist in the pore water. These issues need to be addressed immediately in order to provide meaningful solute transport information. Experiments conducted in cores and small blocks of tuff are required. 


\section{PRELIMINARY EXPERIMENTS}

Initial experiments are required prior to a full-scale heater experiment. The purpose of the initial experiments is to develop methodologies and procedures suitable for monitoring thermohydrologic processes in unsaturated rock. The preliminary nonisothermal experiments incrementally increase complexities from a thermal disturbance an unfractured rock, to an experiment in a rock that includes a single fracture. These two experiments are intended to serve as precursors to a larger field experiment which incorporates multiple fractures in an unsaturated rock mass.

The following sections first describe the two preliminary experiments and then address design issues that require resolution during the preliminary experiments. In addition, experimental procedures are presented.

\subsection{Types of Experiments}

Two preliminary experiments are suggested to evaluate and model less complex nonisothermal flow environments. By limiting the field experiments to avoid ambiguities related to complicated geologic variability, the experiments allow models of simpler systems to be evaluated. As uncertainties are minimized, then fundamental relationships between coupled processes may be estimated, thus avoiding inconclusive results. Figure 5 presents a schematic diagram of the preliminary experiments.

The first preliminary experiment is a nonisothermal experiment in a shallow borehole in unfractured, unsaturated tuff at the Apache Leap Tuff Site. The test would be conducted over a period of several months, and the expected radius of thermal influence is anticipated to be one or two meters. The precise configuration, heater schedule and monitoring locations and variables are discussed below. The purpose of this test is to perform an experiment under well controlled conditions where complex interactions resulting from the presence of a discrete fracture can be minimized. An experiment on this scale should provide the capability to extent laboratory studies to field conditions where more complex boundary conditions may be present.

The second preliminary experiment is a nonisothermal experiment to be conducted under similar conditions to the first experiment, but with a single fracture present. The heat source would be installed at a borehole location that intersects the fracture. The test would be conducted over a similar time period as the first, with perhaps a larger radius of thermal influence. The purpose of this second test is to introduce additional complexity and to evaluate conceptual models, technological capabilities, and process definition. The essential feature of the second test is the added complexity resulting from heat, gas, liquid and solute transport in the discrete fracture.

\subsection{Design Issues}

Preliminary experiments offer the opportunity to evaluate experimental designs, including those identified in Table 6. Of particular concern is the ability to identify initial and boundary conditions during the test, along with material properties of the rock mass. The measurement of state variables is another priority for determining the system response to the imposed thermal source. 


\section{Experiment 1}

Unfractured Rock Heater Experiment

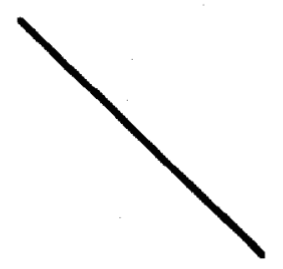

Monitor Initial Conditions

Obtain Characterization Data

Control Boundary Conditions

Install Heater

Conduct Experiment
Experiment 2

Single Fracture Heater Experiment

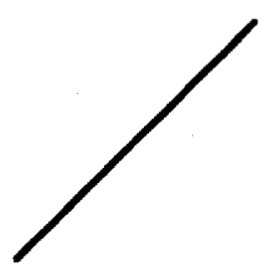


TABLE 6

Experimental Design Issues

\section{Initial Conditions}

- Wet or dry drilling to minimize water content changes within rock.

- Period of time required to allow drilling alterations to dissipate.

\section{Upper Boundary Conditions}

- Covering surface to inhibit water infiltration and evaporation.

- Insulating surface to reduce temperature changes.

\section{Borehole Placement}

- Orientation of heater borehole to prevent chimney effect.

- Diameter, location and orientation of observation boreholes.

- Packer material and locations.

Operation of Heater

- Constant or variable power, constant or variable temperature.

- Duration of heater operation.

- Type of packer materials and packer location.

- Depth of heater

Types of Measurements

- Types of sensors

- Degree of redundancy

- Location and number

- Single vs. cross hole requirements. 


\subsection{Instrument Installation - Preliminary Experiment}

Two types of boreholes should be employed for the heater experiment, a heater borehole and monitoring boreholes. The locations and the drilling methods for installing the boreholes should be finalized using computer simulation models described in a previous section. The orientation, diameter and depth of the heater and observation boreholes are important design aspects in that the boreholes must be situated in such a manner that they monitor system changes in regions were the most significant influences are occurring, yet at the same time the boreholes must not interfere with the test. Simulation models should be employed to evaluate the magnitude of system changes, and determine whether the boreholes can be located to measure these changes. The packer material and locations need to be evaluated to determine the effect of various sampling intervals and sealing techniques on observations. An important concern is the potential for gas flow through an open borehole to occur, which could result in enhanced heat transport away from the heater source to the ground surface.

Temperatures and matric potentials should be collected using thermistors and thermocouple psychrometers, respectively. Thermistors should be placed within the heated interval to monitor rock surface temperatures. Rock extension due to heating should also be monitored using displacement transducers. Replication of instrumentation is essential, with multiple equipment located next to each other in each sample interval. Packers should be used to isolate monitoring intervals. Water content data in the rock matrix surrounding observation boreholes should be collected using devices such as neutron probes and time-domain reflectometers, while geophysical techniques should be employed to provide information deeper into the rock matrix between boreholes. Also, tracers added to the system can be used to gather information on geochemical processes. Monitoring tools such as geophysical arrays, geophones, and permeability tests can be employed to identify changes in fracture saturation as well as rock matrix properties. The schedule for obtaining the measurements are design variables.

Field data concerning temperatures, water contents and air composition and pressure should be collected in both the heater and observation boreholes. It is proposed that intensive sampling of water contents fractures and fracture zones be performed above and around heating borehole at various distances. Intensive sampling of the matrix around fractures and fracture zones should also be performed. It is recommended that moderate sampling be performed of the rock matrix away from fractures, as well as laterally and below the heating borehole. Once the size and location of the fracture zones have been identified, various monitoring and sampling strategies should be examined and tested prior to conducting the field-scale heater experiment. The ability of a relatively simple model which accounts only for heat conduction and treats the rock as a uniform continuum should be examined using thermal parameters estimated from laboratory core experiments.

Both heater and sensor assemblies should be installed in the boreholes. The heater assembly should consist of:

- A power source to supply electricity;

- Current and voltage meters to measure delivered power;

- An electrical heater element to convert electrical energy into thermal energy;

- Packers to prevent gas, liquid and thermal movement in the heater borehole;

- Thermistors to measure rock temperatures along the heater borehole;

- Gas sampling ports to allow measurement of gas pressure in heater interval, and to obtain samples for gas composition analysis; and

- Metal coupons of various composition to evaluate corrosion.

The heater assembly should be recoverable, but should not be removed during the heating phase unless a system failure occurs. Before and after the heating phase, the heater assembly should be removed -ariodically to obtain water content measurements. 
The sensor assemblies should consist of:

- Packers to prevent gas, liquid and thermal movement in the sensor borehole;

- Thermistors to measure rock temperatures along the sensor borehole;

- Gas sampling ports to allow measurement of gas pressure in sensor interval, and to obtain samples for gas composition analysis; and

- Metal coupons of various composition to evaluate corrosion.

The sensor assemblies should be recoverable and should be removed periodically before, during and after the heater experiment in order to obtain water content measurements.

The heater and sensor assemblies should be installed at least several weeks prior to the heater experiment. Baseline temperature, gas pressure, and gas composition measurements should be obtained prior to initiation of the experiment. Once sufficient baseline data have been collected, the heater should be activated causing a thermal perturbation in the system. Continuous measurements of temperatures and total gas pressures should be obtained during the course of the experiment. Occasionally, the sensor assemblies should be removed in order to obtain water content measurements.

The heater should have a strength of between 0.1 and $5 \mathrm{~kW}$, and be able to fit down the heater borehole with a possible diameter of $10 \mathrm{~cm}$ and a possible length of from one to three meters. The size, orientation, and strength of the heater are important design issues. The heater should be isolated using packers, of selected length and composition. The heater source term could either operated as a constant heat flux, or a constant temperature during the heating phase. It is proposed that the heater be operated in a step-wise manner, changing the output strength in increments so that temperatures of 80 to $90^{\circ} \mathrm{C}$ are achieved during the first step, and up to $200^{\circ} \mathrm{C}$ is achieved in the final step. During the cooling phase the heater strength could be either slowly or quickly reduced.

A stepped experiment is also possible in which the heater source is incrementally increased. Each step-wise increase is monitored and used for model evaluation. If the simulation forecasts do not adequately predict observed behavior during a particular step, then individual models can be calibrated using the information collected for that step. After a predetermined time period, the heater source is again increased to provide additional data.

Data collection should be automated to the greatest practical extent in a central computerized installation located at the field site. Relevant data includes power consumption by the heater, temperature measurements, and total gas pressures. Neutron water content measurements should be recorded manually, but should be entered into a computerized database system immediately after data collection. Auxiliary data obtained at infrequent intervals, such as geophysical measurements and precipitation depths should be recorded and entered into the computerized database system as quickly as practically possible. 


\section{REFERENCES}

Ashworth, E. and T. Ashworth, 1990, "A Rapid Method for Measuring Thermal Conductivity of Rock Cores and its Preliminary Use for Finding the Thermal Resistance of Cracks", Rock Mechanics Contributions and Challenges, Hustrulid and Johnson (eds), Balkema, Rotterdam, p. 613-620.

Ashworth, E. and T. Ashworth, 1984, "Application of Finite-Element Analysis for Comparison of In-Situ and Laboratory Measurements of Rock Thermal Properties", Third Int. Mine Ventilation Conf., Harrogate, England, p. 343-347.

Brady, B.H., S.H. Hsiung, A.H. Chowdhury, and J. Philip, 1990, "Verification Studies on the UDEC Computational Model of Jointed Rock", Conference, Aachen, Germany.

Bouyoucos, G.J., 1915, "Effect of Temperature on the Movement of Water Vapor and Capillary Moisture in Soils", J. Agri. Res., 5:141-172.

Buscheck, T.A. and J.J. Nitao, 1990, "Modeling Hydrothermal Flow in Variably Saturated, Fractured, Welded Tuff During the Prototype Engineering Barrier System Field Test of the Yucca Mountain Project", Proc. TOUGH Workshop, Berkeley, CA.

Butkovich, T.R. and W.C. Patrick, 1985, Post-Test Thermomechanical Calculations and Preliminary Data Analysis for the Spent Fuel Test - Climax, Lawrence Livermore National Laboratory, UCRL-53688, 55 pp.

Cassel, D.K., D.R. Nielsen and J.W. Biggar, 1969, "Soil-Water Movement in Response to Imposed Temperature Gradients", Soil Sci. Soc. Amer. Proc., 33:493-500.

Childs, S.W. and G. Malstaff, 1982, "Final Report - Heat and Mass Transfer in Unsaturated Porous Media", Pacific Northwest Laboratory, PNL-4036.

Chuang, Y., W.R. Haldeman, T.C. Rasmussen, and D.D. Evans, 1990, "Laboratory Analysis of Fluid Flow and Solute Transport Through a Variably Saturated Fracture Embedded in Porous Tuff", NUREG/CR5482.

CNWRA, Center for Nuclear Waste Regulatory Analyses, 1991, "Report on Research Activities for Calendar Year 1990", Center for Nuclear Waste Regulatory Analyses, San Antonio, Texas, CNWRA 90-01A.

Cullinan, S.R., 1983, "Non-Isothermal Vapor Transport in a Single Unsaturated Rock Fracture", M.S. Thesis, University of Arizona, Tucson, $59 \mathrm{pp}$.

Daily, W. and A. Ramirez, 1989, "Evaluation of Electromagnetic Tomography to Map in Situ Water in Heated Welded Tuff", Water Resour. Res., 25(6):1083-1096.

Davies, B.E., 1987, "Measurement of Thermal Conductivity and Diffusivity in an Unsaturated, Welded Tuff", M.S. Thesis, University of Arizona.

deMarsily, G., 1981, "Quantitative Hydrogeology", Academic Press, Inc., 440 pp.

Doughty, C. and K. Pruess, 1988, "A Semianalytical Solution for Heat-Pipe Effects Near High-Level Nuclear Waste PAckages Buried in Partially Saturated Geological Media", Int. J. Heat Mass Transfer, 31(1):7990.

Eaton, R.E., N.E. Bixler, and D.C. Reda, 1987, "Coupled Hydrothermal Flows of Liquid and Vapor in Welded Tuff: Numerical Modeling of Proposed Experiment", in Coupled Processes Associated with Nuclear Waste Repositories, Academic Press, Inc., p. 409-420.

Evans, D.D., 1983, "Unsaturated Flow and Transport Through Fractured Rock - Related to High-Level Waste Repositories", NUREG/CR-3206.

Evans, D.D. and C. Huang., 1983, "Role of Desaturation on Transport Through Fractured Rock", Role of the Unsaturated Zone in Radioactive and Hazardous Waste Disposal, Ann Arbor, p. 165-178.

Evans, D.D. and T.J. Nicholson, 1987, "Flow and Transport Through Unsaturated Fractured Rock: An Overview", in Flow and Transport Through Unsaturated Fractured Rock, AGU Geophysical Monograph 42, p. 1-10.

Evans, D.D. and T.J. Nicholson (eds.), 1987, "Flow and Transport Through Unsaturated Fractured Rock", AGU Geophysical Monograph 42, 187 pp. 
Evans, D.D., T.C. Rasmussen, and T.J. Nicholson, 1987, "Fracture System Characterization for Unsaturated Rock", Waste Management '87, 2:209-212.

Evans, D.D. and T.C. Rasmussen, 1988, "Unsaturated Fractured Rock Flow Model Calibration for a Tuff Site", Validation of Flow and Transport Models for the Unsaturated Zone, Ruidoso, N.M., NMSU, p. 96-104.

Evans, D.D. and T.C. Rasmussen, 1991, "Unsaturated Flow and Transport Through Fractured Rock Related to High-Level Waste Repositories, Final Report - Phase III", NUREG/CR-5581, 75 pp.

Green, R.T. and D.D. Evans, 1985, "Radionuclide Transport as Vapor Through Unsaturated Fractured Rocks", Memoirs of Congress on Hydrology of Rocks of Low Permeability, International Association of Hydrogeologists, Tucson, Az., 17(1):254-266.

Green, R.T. and D.D. Evans, 1987, "Radionuclide Transport as Vapor Through Unsaturated Fractured Rock", NUREG-CR-4654, 163 pp.

Green, R.T., W.L. Filipone, and D.D. Evans, 1987, "Effect of Electric Fields on Vapor Transport Near a High-Level Waste Canister", Coupled Processes Associated with Nuclear Waste Repositories, Academic Press, Inc., p. 421-432.

Green, Ronald T., R.H. Martin, and S.Svedeman, 1990, "Use of TOUGH Computer Code to Simulate a Laboratory-Scale Experiment", TOUGH Users Group Workshop, Berkeley, Ca, September 13-14.

Gurr, C.G., T.J. Marshall and J.T. Hutton, 1952, "Movement of Water in Soil Due to a Temperature Gradient", Soil Sci., 74:335-345.

Haldeman, W.R., Y. Chuang, T.C. Rasmussen, and D.D. Evans, 1991, "Laboratory Analysis of Fluid Flow and Solute Transport Through a Fracture Embedded in Porous Tuff", Water Resour. Res., 27(1):53-65.

Hsiung, S.M. A.H Chowdhury, J. Philip, S.D. McKinnon, and B.W. Vanzant, 1991, "Field Investigations for Seismic Effects on Mechanical and Geohydrologic Response of Underground Structures in Jointed Rock", International High Level Radioactive Waste Management Conference, Las Vegas, NV, 8 pp.

Huang, C. and D.D. Evans, 1985, "A 3-Dimensional Computer Model to Simulate Fluid Flow and Contaminant Transport Through a Rock Fracture System", NUREG/CR-4042, 109 pp.

Kilbury, R.K., T.C. Rasmussen, D.D. Evans, and A.W. Warrick, 1986, "Water and Air Intake Measurement Technique for Fractured Rock Surfaces", Water Resour. Res., 22(10):1431-1443.

Lin, W., 1991, "Variation of Permeability with Temperature in Fractured Topopah Spring Tuff Samples", International High Level Radioactive Waste Management Conference, Las Vegas, NV, p. 988.

McCartin, T., R. Codell, T. Nicholson and T. Rasmussen, 1990, "Two-Phase Flow and Solute Transport Simulations in a Tuff Drillcore", TOUGH Users Group Workshop, Berkeley, Ca, September 13-14.

Montan, D.N. and W.C. Patrick, 1986, "Post-Test Thermal Calculations and Data Analyses for the Spent Fuel Test - Climax", Lawrence Livermore National Laboratory, UCRL-53728, 71 pp.

Munson, D.E., 1983, Test Plan: 18-W/m² Mockup for Defense High-Level Waste (DHLW), Sandia National Laboratories, $233 \mathrm{pp}$.

Patrick, W.C., 1986, "Spent Fuel Test - Climax: An Evaluation of the Technical Feasibility of Geologic Storage of Spent Nuclear Fuel in Granite", Lawrence Livermore National Laboratory, UCRL-53702.

Peterson, D.W., 1961, "Dacitic Ash-Flow Sheet Near Superior and Globe, Arizona", Ph.D. Dissertation, Stanford University.

Philip, J.R. and D.A. deVries, 1957, "Moisture Movement in Porous MAterials under Temperature Gradients", Trans. Amer. Geophys. Union, 38:222-232.

Pollock, D.W., 1986, "Simulation of Fluid Flow and Energy Transport Processes Associated with High-Level Radioactive Waste Disposal in Unsaturated Alluvium", Water Resour. Res., 22(5):765-775.

Pruess, K., J.S.Y. Wang, and Y.W. Tsang, 1990, "On Thermohydrological Conditions Near High-Level Nuclear Wastes Emplaced in Partially Saturated Fractured Tuff, 1. Simulation Studies with Explicit Consideration of Fracture Effects", Water Resour. Res., 26(6):1235:1248.

OECD, Organization for Economic Co-Operation and Development, 1990, "The International INTRAVAL Project, Background and Results", Nuclear Energy Agency, Paris, France, 45 pp.

Ramirez, A.L. and W.D. Daily, 1987, "Evaluation of Alterant Geophysical Tomography in Welded Tuff", in Geophysical Investigations of Radioactive Waste Disposal Sites in the Western United States, Journal of Geophysical Research, 92(B8):7843-7853. 
Ramirez, A.L., 1990, Prototype Engineered Barrier System Field Tests (PEBSFT) - Final Report, Lawrence Livermore National Laboratory, UCRL-ID-106159, 104 pp.

Ramirez, A.L., T.A. Buscheck, R. Carlson, W. Daily, V. Latorre, K. Lee, W. Lin, N. Mao, D. Towse, T. Ueng, and D. Watwood, 1990, "Prototype Heater Test of the Environment Around a Simulated Waste Package", International High Level Radioactive Waste Management Conference, Las Vegas, NV, 2:870881.

Rasmussen, T.C., C. Huang, and D.D. Evans, 1985, "Numerical Experiments on Artificially Generated, Three-Dimensional Fracture Networks: An Examination of Scale and Aggregation Effects", Memoirs of Congress on Hydrology of Rocks of Low Permeability, International Association of Hydrogeologists, Tucson, Az., 17(2):676-682.

Rasmussen, T.C., 1986, "Improved Site Characterization Using Multiple Approaches", Groundwater Flow and Transport Modeling for Performance Assessment of Deep Geologic Disposal of Radioactive Waste: A Critical Evaluation of the State of the Art, NUREG/CP-0079, pp. 101-113.

Rasmussen, T.C. and D.D. Evans, 1987, "Unsaturated Flow and Transport Through Fractured Rock Related to High-Level Waste Repositories", NUREG/CR-4655, 474 pp.

Rasmussen, T.C., 1987a, "Computer Simulation of Steady Fluid Flow and Solute Transport Through ThreeDimensional Networks of Variably Saturated, Discrete Fractures", in Flow and Transport Through Unsaturated Fractured Rock, AGU Geophys. Monograph 42, p. 107-114.

Rasmussen, T.C., 1987b, "Meso-Scale Estimates of Unsaturated Fractured Rock Fluid Flow Parameters", Rock Mechanics: Proceedings of the 28th US Symposium, A.A. Balkema, p. 525-532.

Rasmussen, T.C., Guo Zede, and D.D. Evans, 1988, "Unsaturated Hydraulic Properties of the Apache Leap Tuff Matrix", Validation of Flow and Transport Models for the Unsaturated Zone, Ruidoso, N.M., NMSU, p. 334-339.

Rasmussen, T.C. and D.D. Evans, 1989, "Fluid Flow and Solute Transport Modeling Through ThreeDimensional Networks of Variably Saturated Discrete Fractures", NUREG/CR-5239.

Rasmussen, T.C, T.-C.J. Yeh, and D.D. Evans, 1989, "Effect of Variable Fracture Permeability/Matrix Permeability Ratios on Three-Dimensional Fractured Rock Hydraulic Conductivity", in Geostatistical, Sensitivity, and Uncertainty Methods for Ground-Water Flow and Radionuclide Transport Modeling, by B.E. Buxton (ed.), Battelle Press, p. 337-358.

Rasmussen, T.C., D.D. Evans, P.J. Sheets and J.H. Blanford, 1990, "Unsaturated Fractured Rock Characterization Methods and Data Sets at the Apache Leap Tuff Site", NUREG/CR-5596.

Rasmussen, T.C., 1991, "Steady Fluid Flow and Travel Times in Partially Saturated Fractures Using a Discrete Air-Water Interface", Water Resour. Res., 27(1):67-76.

Schrauf, T.W. and D.D. Evans, 1986, "Laboratory Studies of Gas Flow Through a Single Natural Fracture", Water Resour. Res., 22(7):1038-1050.

Smith, S.J., 1989, "Natural Airflow Through the Apache Leap Tuff near Superior, Arizona", M.S. Thesis, University of Arizona.

Taylor, S.A. and J.W. Cary, 1960, "An Analysis of the Simultaneous Flow of Water and Heat or Electricity with the Thermodynamics of Irreversible Processes", Trans. Intern. Congr. Soil Sci., 7th Congr., Madison, Wis., 1:80-90.

Taylor, S.A. and L. Cavazza, 1954, "The Movement of Soil Moisture in Response to Temperature Gradients", Soil Sci. Soc. Amer. Proc., 18:351-358.

Thornburg, T.M., 1990, "Electrical Resistivity of Unsaturated, Fractured Tuff: Influence of Moisture Content and Geologic Structure", M.S. Thesis, University of Arizona, Tucson, Arizona.

Tidwell, V.C., T.C. Rasmussen, and D.D. Evans, 1988, "Saturated Hydraulic Conductivity Estimates for Fractured Rock in the Unsaturated Zone", Validation of Flow and Transport Models for the Unsaturated Zone, Ruidoso, N.M., NMSU, p. 414-421.

Trombel, J.M., 1973, "Thermal Gradients and Water Transfer in Unsaturated Soil", Ph.D. Dissertation, University of Arizona, Tucson, Arizona.

U.S. DOE, 1988, "Site Characterization Plan: Yucca Mountain Site, Nevada Research and Development Area, Nevada", Office of Civilian Radioactive Waste Management, DOE/RW-0199. 
Weber, D.S. and D.D. Evans, 1988, "Stable Isotopes of Authigenic Minerals in Variably-Saturated Fractured Tuff", NUREG/CR-5255.

Wilder, D.G. and J.L. Yow, Jr., 1984, Structural Geology Report, Spent Fuel Test - Climax, Nevada Test Site, Lawrence Livermore National Laboratory, UCRL-53381, 43 pp.

Wilder, D.G. and J.L. Yow, Jr., 1987, Geomechanics of the Spent Fuel Test - Climax, Lawrence Livermore National Laboratory, UCRL-53767, 84 pp.

Yeh, T.C.J., T.C. Rasmussen and D.D. Evans, 1988, "Simulation of Liquid and Vapor Movement in Unsaturated Fractured Rock at the Apache Leap Tuff Site: Models and Strategies", NUREG/CR-5097, $73 \mathrm{pp}$.

Zimmerman, R.M. and M.L. Blanford, 1986, "Expected Thermal and Hydrothermal Environments for Waste Emplacement Holes Based on G-Tunnel Heater Experiments", Rock Mechanics: Key to Energy Production, Proc. 27th U.S. Symp. Rock Mech., Tuscaloosa, AL, edited by H.L. Hartman, pp 874-882. 


\begin{tabular}{|c|c|}
\hline $\begin{array}{l}\text { U.S. NUCLEAR REGULATORY COMMISSION } \\
\text { BIBLIOGRAPHIC DATA SHEET } \\
\text { (See instructions on the reverse) }\end{array}$ & \multirow[t]{2}{*}{$\begin{array}{l}\text { 1. REPORT NUMBER } \\
\text { (Asulgnod by NRC. Add Vol, Supp., Rov., } \\
\text { and Addondum Numbers, if ony.) } \\
\text { NUREG/CR-5880 }\end{array}$} \\
\hline \multirow{4}{*}{$\begin{array}{l}\text { 2. TITLE AND SUBTITLE } \\
\text { Nonisothermal Hydrologic Transport Experimental Plan }\end{array}$} & \\
\hline & DATE REPORT PUBLISHED \\
\hline & \begin{tabular}{|c|c|} 
MONTH & YEAR \\
September & 1992
\end{tabular} \\
\hline & $\begin{array}{l}\text { 4. FIN OR GRANT NUMBER } \\
\text { FIN L1282 }\end{array}$ \\
\hline \multirow{3}{*}{$\begin{array}{l}\text { 5. AUTHOR(S) } \\
\text { T. C. Rasmussen, D. D. Evans }\end{array}$} & 6. TYPE OF REPORT \\
\hline & Technical \\
\hline & Nov. 1989 - June 1992 \\
\hline \multicolumn{2}{|l|}{$\begin{array}{l}\text { 8. PERFORMING ORGANIZATION - NAME AND ADDRESS (If NRC, provide Division, Offic } \\
\text { name and mailing address) } \\
\text { Department of Hydrology and Water Resources } \\
\text { University of Arizona } \\
\text { Tucson, Arizona } 85721\end{array}$} \\
\hline \multicolumn{2}{|c|}{$\begin{array}{l}\text { 9. SPONSORING ORGANIZATION - NAME AND ADDRESS /ff NRC, rype "Same as above"; if contractor, provide NRC Division, Office or Region, U.S. Nuclear Regulatory Commission. } \\
\text { Division of Regulatory Appl ications } \\
\text { Office of Nuclear Regulatory Research } \\
\text { U.S. Nuclear Regul atory Commission } \\
\text { Washington, DC } 20555\end{array}$} \\
\hline \multicolumn{2}{|l|}{ 10. SUPPLEMENTARY NOTES } \\
\hline \multicolumn{2}{|c|}{$\begin{array}{l}A^{1 .} \text { ASSTEACT (200 yordsorless) } \\
\text { processes in unsaturated fractured rock related to the disposal of high-level radioac- } \\
\text { tive waste (HLW) in an underground repository. The experimental plan provides a } \\
\text { methodology for obtaining data required for evaluating conceptual and computer models } \\
\text { related to HLW isolation in an environment where significant heat energy is produced. } \\
\text { Coupled-process models are currently limited by the lack of validation data appropriate } \\
\text { for field scales that incorporate relevant transport processes. Presented in this } \\
\text { document is a discussion of previous nonisothermal experiments. Processes expected to } \\
\text { dominate heat-driven liquid, vapor, gas, and solute flow during the experiment are } \\
\text { explained, and the conceptual model for nonisothermal flow and transport in unsaturated, } \\
\text { fractured rock is described. of particular concern is the ability to conform the } \\
\text { hypothesized conceptual model, specifically, the establishment of higher water satura- } \\
\text { tion zones within the host rock around the heat source, and the establishment of } \\
\text { countercurrent flow conditions within the host rock near the heat source. Field } \\
\text { experimental plans are presented using the Apache Leap Tuff Site to illustrate the } \\
\text { implementation of the proposed methodology. Both small-scale preliminary experiments } \\
\text { and a long-term experiment are described. }\end{array}$} \\
\hline \multirow{4}{*}{$\begin{array}{l}\text { 12. KEY WORDS/DESCR:PTOAS IList words or phrases that will assist researchers in locating the repon.) } \\
\text { computer models } \\
\text { countercurrent flow } \\
\text { field heater experiment } \\
\text { high-level radioactive waste disposal } \\
\text { hydrologic transport processes } \\
\text { noni sothermal flow } \\
\text { unsaturated, fractured rock } \\
\text { vapor phase transport }\end{array}$} & \begin{tabular}{l|l} 
13. AVAILABILITY STATEMENT \\
Unl imited
\end{tabular} \\
\hline & $\begin{array}{l}\text { 14. SECURITY CLASSIFICATION } \\
\text { Unhis Pagel } \\
\text { Unclassified } \\
\text { IThis Report } \\
\text { Unclassified }\end{array}$ \\
\hline & 15. NUMBER OF PAGES \\
\hline & \\
\hline
\end{tabular}

